This PDF is a selection from a published volume from the National Bureau of Economic

Research

Volume Title: Risk and Capital Adequacy in Commercial Banks

Volume Author/Editor: Sherman J. Maisel, editor

Volume Publisher: University of Chicago Press

Volume ISBN: 0-226-50281-3 (cloth); 0-226-50282-1 (paper)

Volume URL: http://www.nber.org/books/mais81-1

Conference Date:

Publication Date: 1981

Chapter Title: The Fundamental Determinants of Risk in Banking Chapter Author(s): Barr Rosenberg, Philip R. Perry

Chapter URL: http://www.nber.org/chapters/c13534

Chapter pages in book: (p. 367 - 407) 


\title{
16 The Fundamental \\ Determinants of \\ Risk in Banking
}

\author{
Barr Rosenberg and Philip R. Perry
}

\subsection{Introduction}

A complete model of the joint probability distribution of prices and volumes of bank assets and liabilities, incorporating those aspects of management and financial structure which influence bank success, would predict banking risk as a function of regulatory parameters. From the model, optimal regulatory strategy could be derived. However, many of the data necessary to estimate the joint distribution are not available, and, even where data are available, sample size is often inadequate. An appealing alternative is to seek an empirical relationship between the probability distribution of outcomes and available "descriptors" of banking activity. The descriptors can be chosen, insofar as possible, to approximate the variables that would enter into a complete and correctly specified model - at the same time, they can be constructed to minimize the effects of measurement error in available data and to provide surrogates for unreported items.

Three topics relating to banking risk can be distinguished: First, What is the magnitude of each bank's risk relative to the industry norm, and what fundamental determinants of individual bank risk can be identified? Second, What is the industry risk level and what causes this to fluctuate? Third, What common factors influence groups of banks differentially from others and how much risk is attached to each factor? We have planned three studies, one with reference to each topic. The first study is contained in this chapter.

Barr Rosenberg is professor at the Berkeley Business School, University of California, Berkeley. Philip R. Perry is assistant professor at the School of Management, State University of New York at Buffalo.

We gratefully acknowledge the comments of Sherman Maisel, Vinay Marathe, David Pyle, and William Sharpe, and the Management Sciences Department of Wells Fargo Bank. Responsibility for errors is, of course, our own. 
Cross-sectional time-series data for a panel of banks, derived largely from the compustat data base, are used in all studies. Individual bank data are required for the first and third studies, which focus on differences between banks. The estimated relationships, when aggregated across the industry, predict the industry risk level. This indirect prediction is potentially the most powerful approach to the second topic, for the greater variability of explanatory variables across disaggregated data allows more accurate parameter estimation than can be obtained from timeseries variation in industry data alone. However, this indirect approach involves extrapolation of a relationship across banks at one point in time to predict the effects of changes over time in the industry norm, a method that must be scrutinized carefully and adopted cautiously.

The risks to the bank's depositors, creditors, insurers, and owners all hinge upon the present value of the bank. As long as the present value as an ongoing enterprise is positive, some form of reorganization can presumably be found that fully satisfies the claims of those who hold the bank's liabilities and that returns the net present value to the stockholders. When net present value drops below zero, claim holders will suffer to varying degrees, but net present value is still the single most important determinant of the magnitude of their losses. Thus the essential target for any study of banking risk is the probability distribution of present value.

Two measures of changes in present value are available: reported earnings - the accountant's measure-and change in the market value of the bank's capital - the economist's measure. We have elected to work with changes in market value. Market values of senior liabilities (bonded debt and preferred stock) are difficult to obtain for most of the historical sample. Since senior liabilities are generally a small portion of bank capital, and since proportional variability in their value is small in comparison with proportional variability of common stock (unless the bank is in severe trouble), senior liabilities can be neglected, with the proportional change in common stock value serving as a surrogate for the whole. The proportional change in value of the common stock, which is the investment return to the common stockholder, becomes the variable for which risk must be predicted.

When investment return is compared with earnings as an indicator of unpredictable outcomes, the advantages of investment return are frequency and timeliness, serial independence, and lack of bias. Investment returns provide frequent and timely observations of unpredictable events, since an event that influences the bank is incorporated into its stock price as soon as the event is recognized and its value appraised. Thus, if twelve monthly returns are observed, each return is likely to reflect the unanticipated events in that month. Such events would not be reflected in accounting earnings until quarterly or annual statements were prepared, and they are often deferred to later fiscal years. (For example, 
a gain or loss owing to fluctuation in the dollar value of an international debt when the exchange rate changes is sometimes amortized over the life of the debt.)

Investment returns tend to lack serial correlation, because, as each forthcoming trend in bank earnings is discerned, its estimated discounted value is immediately reflected in stock price. By contrast, the effects of the trend may show up as a smooth, serially correlated disturbance in earnings extending over many years. Moreover, accounting procedures allow earnings to be "smoothed" from quarter to quarter and year to year, so that even when the true events are serially independent their effects can be flattened into smooth and serially correlated perturbations in reported earnings.

Finally, the current value of the bank's common stock is not intrinsically biased, when viewed as an estimator of true present value. Both positive and negative errors permit profit to traders aware of the discrepancy and are therefore self-destroying. Accounting principles, on the other hand, often deliberately ignore a component of earnings that is difficult to evaluate, with the result that reported earnings are a valid estimate of total earnings exclusive of that component but a biased estimate of the total. For example, the unrealized inflation-caused increase in the market value of a bank's real property is excluded from reported earnings.

These defects of reported earnings force the use of investment returns as a means of studying unpredictable events. A ten-year history of investment returns provides 120 largely independent observations on variance per unit time, whereas a ten-year history of reported earnings may provide the equivalent of fewer than ten biased observations, after problems of timeliness and serial dependence have been dealt with. Reported earnings can at best serve to capture the impact of cataclysmic and enduring events, whereas investment returns not only capture these but are also a window on smaller transitory outcomes that are no less important in a cumulative sense.

The advantages of accounting earnings are traditional visibility and precision. Some professionals in banking distrust the market value of bank common stock, believing it to be a product of market whims. Earnings, though subject to the arbitrariness of accounting conventions, are preferred because those conventions are familiar, but the analytical process resulting in market value is obscure and decentralized. In response to this objection, one can cite negative evidence, in that studies of stock market prices have failed to find gross inefficiencies, and also positive evidence: if one believes that market valuation is ill informed, one has the opportunity for speculative profit. The act of speculative trading moves price toward correct present value-for instance, if price is below present value, the speculator buys the stock, thereby increasing 
demand and raising price. It is precisely this opportunity for all those possessed of information to profit from a discrepancy between market value and present value that encourages confidence in market price as a value measure.

The study reported here, "The Fundamental Determinants of Risk in Banking," is concerned with prediction of the two essential aspects of risk: exposure to systematic risk, or "beta," and the magnitude of residual risk, the "residual standard deviation." Systematic risk dominates in an investor's diversified portfolio and is therefore the aspect of risk that is compensated by excess return in the theory of capital markets. Hence beta is the crucial determinant of the cost of equity capital to the bank. Residual risk, also called diversifiable risk, is the remaining element of risk, independent of systematic risk. Residual standard deviation is the magnitude of the independent variability of the bank's present value and hence expresses the likelihood of problems arising for the bank independently of problems for the economy as a whole.

Seventy-eight descriptors of bank activity are formulated, grouped into categories relating to asset mix, liability $\mathrm{mix}$, other asset/liability characteristics, operating characteristics, earnings success, growth, size, (stock) market price variability, descriptors of many kinds dependent on the market valuation of common stock, and regional variables. The usefulness of the descriptors as indicators of troubled situations is touched upon. Then the predictive power of the descriptors, both singly and in multiple regressions, is reported for beta and for residual risk. The fundamental descriptors as a group capture a large proportion of risk variations between banks. The relationship does not importantly change between the first and second halves of the twelve-year history. Thus the fitted prediction rules provide an appealing risk-forecasting tool.

A study under way, "Changing Risk in Banking," compares two approaches to risk analysis for the industry aggregate. One approach applies stochastic parameter regression to infer industry risk fluctuations from the history of price variability in the Standard and Poor's banking indexes. Here no fundamental concomitants are used. The analysis does show large, statistically significant changes in industry risk over the fifty-year history. However, the standard error of estimate at any one point in time is moderately large, so that the approach cannot be used with confidence to identify year-to-year changes in risk from monthly index returns. Possibly the use of more frequent weekly or daily returns would help in this regard. The second approach aggregates individual bank risk predictions to predict industry risk. The standard error of prediction is smaller in this case, but potential differences between the cross-bank relationship and the relationship over time must be considered. 
A third study, "Common Factors in Banking," attempts to decompose residual risk into two components: the outcome of common factors influencing groups of banks and the remaining risk, specific to individual banks and independent across banks. The distinction is important for regulatory purposes, since a common factor might cause difficulties for many banks at once, whereas specific events will tend to be distributed more randomly and regularly over time. As a by-product of this more sophisticated model of residual risk, the systematic risk model of the first study will be reestimated. The estimated coefficients will probably not change significantly, but the standard errors of the estimates may increase.

\subsection{Overview}

The operating risk in a bank can be precisely defined as the unpredictable variability of the present value of the bank. Risk is most commonly studied by observing changes in the earnings or worth of the firm. Such measures of risk, based as they are upon the bank's accounting practices, accurately capture some aspects of risk but overlook others. For example, changes in the market value of the bank's assets are imperfectly captured. Accounting measures of earnings also tend to smooth the time path of earnings and, in so doing, tend to obscure the fluctuations that can be used to establish the level of risk.

The market value of the bank's liabilities, at any point in time, is an estimate of the present value of the bank. The common stock is a large portion of the long-term capital of most banks, and it is that part with the greatest exposure to changes in the bank's present value. Since accurate measures of the market value of other bank liabilities are lacking, a study of the month-to-month variability in the outstanding value of the bank's common stock becomes a natural approach to measuring bank risk.

Two aspects of the risk of common stock are studied below. The first is the systematic risk as measured by beta. The second is the residual variability, measured by the variance of the stock's residual or unsystematic return. A number of "descriptors" of the bank's operating characteristics are used as predictors for these two risk measures.

Data on more than 100 banks for about 100 months are available; there are 11,219 data points in all. Predictive models for systematic and residual risk are fitted to this pooled cross-sectional time series.

The empirical results are satisfying. The estimated coefficients are generally consistent with our a priori expectations concerning the effects of a bank's operations upon its risk. The coefficients are estimated with fair precision, and a large number of the effects are statistically significant. 
One important measure of the success of the prediction rule is the degree to which fundamental descriptors (descriptors of the operating characteristics of the bank) can substitute for historical risk measures as predictors of future risk. If all operating determinants of risk were perfectly captured, the historical risk measure would become redundant and would make an insignificant contribution to future prediction. Conversely, if the fundamental descriptors were inadequate, the historical risk measure would remain as an important predictor of future risk. In this study the historical risk measures are only marginally significant and add very little to the explanatory power of the fundamental prediction rules.

Two other satisfying aspects of the estimated prediction rules are insensitivity to the time period selected and insensitivity to the inclusion or deletion of various descriptors. We have estimated the models over several time periods and found little change in estimated coefficients. Indeed, "Chow" tests of changed coefficients only weakly reject changes in the structure of the model. Also, deleting insignificant variables or groups of variables of different types generally does not change the signs of the remaining coefficients. This makes it seem less likely that the coefficients of included variables are importantly influenced by surrogate effects for other variables that may have been excluded.

The results of the study may be useful in a number of ways. First, they provide prediction rules for investment risk that have potential usefulness in regulatory practice. Second, the information content of various descriptors is tested: some commonly used descriptors of operating characteristics are found to be important predictors of investment risk and others are not. Third, the risk coefficients for various asset and liability categories are a natural measure of the capital costs that should be associated with them.

The plan of the paper is as follows. Section 16.3 defines the components of risk. Section 16.4 explains the procedure used to fit prediction rules for systematic and residual risk. The exact formulas are given in the Appendix to the paper. Section 16.5 discusses the descriptors that have been employed. Section 16.6 explains the sample. Section 16.7 reports the empirical results, and section 16.8 provides a conclusion.

\subsection{The Components of Risk}

The single-factor, market-index model of security returns has received widespread attention. It has the advantage of simplicity, and it exploits the fact that a large part of the covariance among security returns can be explained by a single factor analogous to a market index. Yet, in a pioneering study, King (1966) concluded that there are important covari- 
ances among security returns beyond those attributable to an overall market factor. His conclusions are consistent with the beliefs of professional portfolio managers and security analysts, who generally agree that there are important components of security returns associated with the economic and financial characteristics of the firm. These components of return influence all (or almost all) firms having the associated characteristics and thereby induce correlations among the returns of different firms possessing such characteristics.

In a recent paper, Rosenberg (1974) developed a multiple-factor model of security returns. This model implies a single-factor, marketindex model of the usual form, which, however, possesses two additional interesting properties: $(a)$ there exists a set of residual factors that contribute additional, or "extramarket," components of covariance among security returns; $(b)$ the familiar beta coefficient (a measure of systematic risk) is a function of the parameters of the underlying multiple-factor model. With the additional assumption that both the specific risk and the factor loadings of the firm are linear functions of known characteristics of the firm, which can be represented by "descriptors" derived from accounting data and stock market price behavior, Rosenberg showed that it is possible to construct a set of transformed factors with loadings identical to the descriptors. These transformed factors may be directly estimated by ordinary regression. This approach - which is the one utilized in this paper-has the advantage of statistical simplicity, and it exploits such information as is available concerning the economic character of the factor loadings.

The single-index model of security returns provides a relationship between returns and two aspects of risk, systematic and specific; the multiple-factor model includes a third type of risk, extramarket covariance. To make this terminology a bit clearer, consider the following explanations of the three types of risk that contribute to security returns-systematic risk, specific risk, and extramarket covariance.

1. Systematic risk arises from the tendency of the asset price to move along with the market index. The amount of systematic risk of any asset is sometimes called its "volatility." The measure of systematic risk is widely known as "beta." If beta is 1 , then the asset price tends to fall in the same proportion that the market falls, other things being equal, and to rise by the same proportion that the market rises. If beta is 1.5 , the asset price tends to fall (or rise) proportionally by one and one-half times as much as the market falls (or rises).

2. Specific risk is the uncertainty in the return of an asset that arises from events that are specific to that firm. It is that part of risk that is due to events in the firm that are unrelated-or, at most, distantly related-to events that influence other firms. A leading example of this kind of risk was provided by the sudden announcement of Franklin National Bank's 
returns for ten deciles of $H \beta$ (shown as ten horizontal steps extending across the decile ranges) decline in an orderly fashion as $H \beta$ increases. When the market falls, the results appear as in figure 16.1. When the market rises, the results appear as if reflected about the axis of zero return: high $H \beta$ stocks show greater positive returns; low $H \beta$ stocks show smaller positive returns.

The criterion for a successful prediction rule for beta is that it accurately arranges stocks in proportion to the response to the market. The closer the fit of the predicted market response for the security to the actual security return, the better is the prediction. Each interval of market movement provides an opportunity to test the accuracy of predictions available at the start of the interval. A succession of monthly intervals provides a long history of evaluations and hence an extensive examination of a prediction rule.

The solid line in figure 16.1 is the line of best fit to the data. However, if we were actually predicting returns using $H \beta$, our predictions would lie along the dashed line. In the case of a stock with predicted beta of zero, predicted return is the riskless rate, which was roughly 4 percent over that six-month period. For other stocks, the predicted return equals the riskless rate plus beta times the market excess return. The measure of success is the degree to which the return predictions for individual stocks lying along the dashed line fit the actual returns. The measure of goodness of fit is the coefficient of determination, or $R^{2}$.

Although the regression line achieves a good fit, there remain large errors about the line. These errors are the manifestation of residual risk, or the residual returns of the stocks. Of course, the residuals are influenced by the predicted betas. If a better rule were used to predict betas, residuals would be typically smaller. Nevertheless, all the improvements that appear to be possible in beta prediction achieve only a small reduction in the magnitude of the typical residual return. Further, we know from a multitude of studies that little of the variance of residual returns can be accounted for by security analysis predictions of mean returns. Hence these residual returns are largely unpredictable elements of return. The problem of predicting residual risk is equivalent to the problem of predicting the expected magnitude (absolute value) of the residual return on a stock. If this expected magnitude is small, the residual risk is small-and conversely.

Figure 16.2 illustrates the prediction of residual risk. On the horizontal axis, the residual risk prediction, defined as the predicted standard deviation of residual return, or $\hat{\sigma}$, is plotted. Stocks with higher levels of risk appear to the right. The vertical axis represents the absolute residual return for the stock. At several points, the expected frequency distribution of residual returns for stocks at that level of residual risk is drawn. Since the absolute value of residual return is under analysis, it will always 


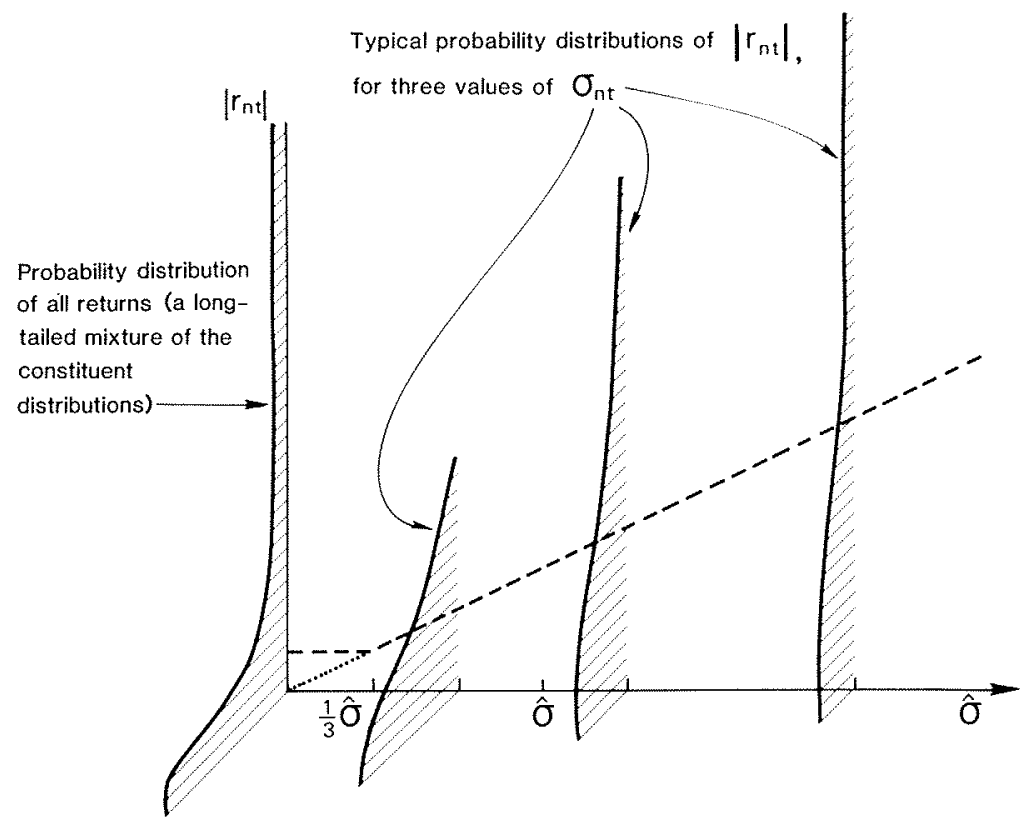

Fig. 16.2 Prediction of cross-sectional differences in variance.

be positive. The shape of the curve is that of half a bell-shaped curve. Even for stocks with very high levels of risk, as in the probability distribution at the right, the most likely residual return lies at the bottom of the bell-shaped half-curve, a residual return of zero. However, for highresidual-risk stocks, there is a possibility of very large residual returns, and so the distribution extends upward to the top of the page. For low-residual-risk stocks, with small $\hat{\sigma}$, we expect a tightly bunched distribution of returns, as in the drawings nearer the vertical axis. The dashed line drawn in the figure plots the predicted mean absolute residual return. This is a constant proportion of the standard deviation ( 76 percent in the model that will be developed below). The small kink in the straight line near zero is explained in the Appendix.

There is a natural statistical procedure to evaluate a prediction rule for residual risk. The dependent variable is the observed absolute residual return for the stock. The independent variables are predictions for the amount of residual risk. If the prediction is successful, then those stocks with high levels of predicted residual risk will show frequent large absolute residual returns, as in the distribution at the extreme right. Conversely, stocks having low levels of predicted risk will exhibit a tight distribution of residual returns, as in the distributions farther to the left. A suitably defined measure of goodness of fit for the regression, analogous to an $R^{2}$, summarizes the success of the prediction rule. This approach is explained in section 16.7 . 


\subsection{The Descriptors: Information Sources Used in Risk Prediction}

In an attempt to predict risk, one can draw on many kinds of information. There are indications of future risk in the current balance sheet and income statement, such as proportions in various asset and liability categories, and operating margins. There are indications of the normal risk of the firm's operations in the historical variability of items in the income statement. When fluctuations obscure a policy of the firm, as in fluctuations over time in the payout ratio owing to transitory earnings fluctuations, a historical average of the policy, such as a five-year cumulative payout ratio, is useful. Trends in variables measure the changing position of the firm and provide some indication of growth orientation. Variables capturing market judgment, expressed as ratios of market values to income-statement or balance-sheet variables, such as "leverage at market value," are often powerful indicators of the market's forecasts of the firm's prospects.

Another important item of information is the regional location and type (e.g., money center, New York) of the bank; we use indicator (dummy) variables for six such groupings. The final category of information is the behavior of the market price of the common stock. Table 16.1 lists the descriptors we have used, along with a brief definition of each; detailed definitions are provided in Rosenberg and Perry (1978). Summary statistics for these descriptors are in table 16.2.

The reader may complain that we are going too far afield in amassing information from so many distinct sources. Why not restrict oneself to a historical measure of the aspect of risk in question? One justification is that it is important to ascertain the fundamental determinants of risk. And the second justification will be found in predictive performance.

A number of principles were observed in constructing the descriptors.

1. No descriptor was employed unless there were compelling a priori grounds to believe it might be predictive of subsequent risk. Such descriptors were found in three categories:

a) Historical statistics on past risk for the bank's stockholders: these may be viewed as estimates (subject to measurement error) of past underlying aspects of risk. As such, they are useful in predicting an aspect of subsequent risk to the degree that both the following conditions are satisfied:

i) the historical estimate is an accurate estimator of the underlying aspect of past risk, not obscured by measurement error;

ii) the historical aspect of risk is correlated with the future aspect of risk that is to be predicted.

b) Fundamental descriptors of the bank's operations and balance sheet, which economic theory leads us to believe are determinants of risk or correlated with risk. These may be subdivided into those that 
A. Descriptors of Asset Mix

1 NCMLDA - THE RATIO OF NET COMMERCIAL LENDING TO ASSETS

2 COMLNA - THE RATIO OF COMMERCIAL LOANS TO ASSETS

3 NCNLDA - THE RATIO OF NET CONSUMER LENDING TO ASSETS

4 CONLNA - THE RATIO OF CONSUMER LOANS TO ASSETS

5 MUNIBA - THE RATIO OF TAX-EXEMPT BONDS TO ASSETS

6 RELNSA - THE RATIO OF REAL ESTATE LOANS TO ASSETS

7 ISECTA - THE RATIO OF ALL INVESTMENT SECURITIES TO ASSETS

8 TRDASA - THE RATIO OF TRADING ACCOUNT SECURITIES TO ASSETS

\section{B. Descriptors of Liability Mix}

9 CONTDA - THE RATIO OF CONSUMER TIME DEPOSITS TO ASSETS

10 DEMNDA - THE RATIO OF DEMAND DEPOSITS TO ASSETS

11 NFFBA - THE RATTO OF (NET) FEDERAL FUNDS BORROWED TO ASSETS

12 FORDPA - THE RATIO OF FOREIGN DEPOSITS TO ASSETS

13 SAVEDA - THE RATIO OF SAVINGS DEPOSITS TO ASSETS

14 TBORA - THE RATIO OF TOTAL BORROWINGS TO ASSETS

15 TCAPA - THE RATIO OF TOTAL CAPITAL TO ASSETS

16 TIMEDA - THE RATIO OF TIME DEPOSITS (OTHER THAN SAVINGS) TO ASSETS

\section{Descriptors of Asset/Liability Characteristics}

17 ATOLB - THE RATIO OF ASSETS TO LONG-TERM LIABILITIES (BOOK VALUE OF EQUTTY, PLUS LONG-TERM DEBT)

18 BLEV - LeVerage, AT BoOK VALUE: THE RATIO OF THE BOOK VAlUe OF (EQUTTY PLUS DEBT) TO THE BOOK VALUE OF EQUITY

19 DILU - POTENTIAL DILUTION: THE RATIO OF NET INCOME PER SHARE FULLY DILUTED TO NET INCOME PER SHARE

20 DTOA - THE RATIO OF TOTAL DEBT TO ASSETS

21 KMTMN - AVERAGE MATURITY OF TAX-EXEMPT BOND PORTFOLIO, IN MONTHS

22 KMTUS - AVERAGE MATURITY OF TAXABLE BOND PORTFOLIO, IN MONTHS

23 KPDEP - THE PERCENTAGE DEPRECIATION IN THE BOND PORTFOLIO: THE RATIO OF THE DIFFERENCE BETWEEN BOND PORTFOLIO MARKET AND BOOK VALUES TO BOND PORTFOLIO BOOK VALUE

24 RLTLTL - THE RATIO OF "RISKY" LIABILITIES TO LONG-TERM LIABILITIES

\section{Descriptors of Operating Characteristics}

25 ATAX - THE RATIO OF INCOME TAXES TO PRETAX INCOME, PAST FIVE YEARS

26 FFMKT - FEDERAL FUNDS MARKET-MAKING ACTIVITY: THE RATIO OF THE MINIMUM OF (FEDERAL FUNDS PURCHASED, FEDERAL FUNDS SOLD) TO ASSETS

27 FLO1 - THE RATIO OF AVERAGE CASH FLOW TO CURRENT LIABILITIES

28 FRGNO - THE RATIO OF FOREIGN OFFICES TO TOTAL OFFICES

29 PAY1 - PAYOUT: THE RATIO OF COMMON DIVIDENDS TO EARNINGS AVAILABLE FOR COMMON THE PRIOR YEAR, PAST FIVE YEARS

30 PNCV - THE ESTIMATED PROBABILITY OF NONCOVERAGE OF FIXED CHARGES USING A TRENDED VALUE FOR CURRENT OPERATING INCOME

31 SALTOR - THE RATIO OF SALARIES AND RELATED EXPENSES TO CURRENT OPERATING REVENUE

32 TRDVRA - THE RATIO OF (THE VARIABILITY [STANDARD DEVIATION] OF TRADING ACCOUNT INCOME $\times 100$ ) TO ASSETS

33 vCAP - THE VARIABILITY OF CAPITAL STRUCTURE: THE RATIO OF THE SUM OF THE ABSOLUTE VALUES OF CHANGES IN THE BOOK VALUES OF EQUITY AND LONG-TERM DEBT TO THE SUM OF THE BOOK VALUES JF EQUITY AND LONG-TERM DEBT

34 VERN - THE VARIABILITY OF EARNINGS: THE RATIO OF THE STANDARD DEVIATION OF EARNINGS TO THE ABSOLUTE VALUE OF AVERAGE EARNINGS

35 VFLO - THE VARIABILITY OF CASH FLOW: THE RATIO OF THE STANDARD DEVIATION OF CASH FLOW TO THE AVERAGE ABSOLUTE CASH FLOW

36 ABET - AN ACCOUNTING BETA, EQUAL TO THE "COEFFICIENT OF EXPLAINED VARIATION" OF THE FIRM'S EARNINGS WITH RESPECT TO ECONOMYWIDE EARNINGS 
Table 16.1 (continued)

E. Descriptors of Earnings Success

37 CUTD - THE AVERAGE PROPORTIONAL CUT IN DIVIDENDS, PAST FIVE YEARS

38 DELE - THE PROPORTIONAL CHANGE IN EARNINGS PER SHARE

39 DMNE - A DUMMY VARIABLE INDICATING NEGLIGIBLE EARNINGS

40 MRGIN - THE RATIO OF NET INCOME TO CURRENT OPERATING REVENUE

41 REVENA - THE RATIO OF CURRENT OPERATING REVENUE TO ASSETS

42 ROEQ - RETURN ON EQUITY: THE RATIO OF NET INCOME TO BOOK VALUE OF EQUTTY, PAST FIVE YEARS

F. Descriptors of Growth

43 AGRO - ASSET GROWTH RATE, EQUAL TO THE RATIO OF THE ANNUAL TREND IN ASSETS TO THE AVERAGE VALUE

44 DMS5 - A DUMMY VARIABLE INDICATING THE AVAILABILITY OF A FIVE-YEAR HISTORY OF EARNINGS INFORMATION

45 EGRO - EARNINGS GROWTH RATE, EQUAL TO THE RATIO OF THE ANNUAL TREND IN EARNINGS TO THE ABSOLUTE VALUE OF THE AVERAGE

46 OFFEX - DOMESTIC OFFICE EXPANSION RATE, EQUAL TO THE RATIO OF THE ANNUAL TREND IN THE NUMBER OF DOMESTIC OFFICES TO THE AVERAGE VALUE

47 RSKLGO - GROWTH RATE OF RISKY LIABILITIES, EQUAL TO THE RATIO OF THE ANNUAL TREND IN RISKY LIABILITIES TO THE AVERAGE VALUE

G. Descriptors of Size

48 ASSI - THE (NATURAL) LOGARITHM OF AVERAGE (PAST FIVE YEARS) TOTAL ASSETS (IN MILLIONS)

49 MKTS - CURRENT OPERATING REVENUE (IN MILLIONS)

H. Descriptors of (Stock) Market Price Variability

50 HBET - HISTORICAL BETA, THE REGRESSION COEFFICIENT TAKEN FROM THE REGRESSION OF MONTHLY COMMON STOCK RETURNS ON MONTHLY RETURNS FOR THE MARKET

51 BTSQ - THE SQUARE OF HBET, DEFINED ABOVE

52 HSIG - HISTORICAL SIGMA, THE STANDARD DEVIATION OF RESIDUAL RETURNS FROM THE REGRESSION FOR HBET, DEFINED ABOVE

53 SGSQ THE SQUARE OF HSIG, DEFINED ABOVE

54 BS - THE SQUARE ROOT OF THE PRODUCT OF HBET AND HSIG, AS DEFINED ABOVE

55 BADJ - THE BAYESIAN ADJUSTMENT TO HBET, DEFINED ABOVE, UNDER THE (ERRONEOUS) ASSUMPTION THAT THE UNDERLYING VALUES OF BETA AND SIGMA ARE INDEPENDENT

56 LPRI - THE (NATURAL) LOGARITHM OF THE STOCK PRICE

57 RSTR - THE LOGARITHMIC RATE OF RETURN OVER THE PAST YEAR

58 TREC - A MEASURE OF COMMON STOCK TRADING RECENCY, EQUAL TO THE RECIPROCAL OF THE NUMBER OF PRIOR YEARS OF AVAILABLE MONTHLY STOCK PRICES

1. Descriptors Dependent upon the Market Valuation of Common Stock

59 ATOLM - THE RATIO OF ASSETS TO LONG-TERM LIABILITIES (MARKET VALUE OF EQUITY, PLUS LONG-TERM DEBT)

60 BBET - "BEAVER" BETA: THE REGRESSION COEFFICIENT TAKEN FROM THE REGRESSION OF THE NORMALIZED EARNINGS/PRICE RATIO OF THE FIRM ON THE NORMALIZED EARNINGS/PRICE RATIO OF THE ECONOMY

61 BTOP - THE RATIO OF BOOK VALUE TO MARKET VALUE OF EQUTTY

62 CAPT - THE (NATURAL) LOGARITHM OF THE MARKET VALUE OF EQUITY (IN MILLIONS)

63 DMYL - A DUMMY VARIABLE INDICATING EXTREMELY LOW DIVIDEND YIELD

64 ENTP - THE NORMALIZED EARNINGS/PRICE RATIO

65 ETOP THE RATIO OF EARNINGS TO PRICE

66 ETP5 - THE "TYPICAL" EARNINGS/PRICE RATIO, PAST FIVE YEARS

67 LIQU - A MEASURE OF LIQUIDITY, EQUAL TO THE RATIO OF (CASH PLUS RECEIVABLES LESS CURRENT LIABILITIES) TO THE MARKET VALUE OF EQUITY 
Table 16.1 (continued)

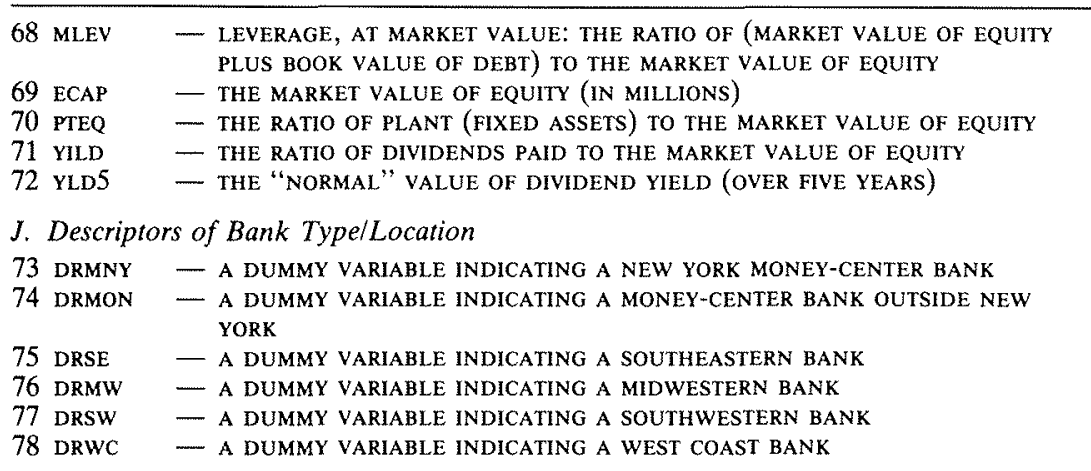

Note: Detailed descriptor definitions are available in NBER Working Paper no. 265.

relate exclusively to business risk, those that relate exclusively to financial leverage, and those that measure the interaction of both.

c) Indicators of the judgment of investors concerning the firm, which provide indirect measures of the bank's risk. Foremost among these are valuation ratios such as book/price and earnings/price (indicative of investors' expectations concerning the bank's future growth and success).

2. The second principle concerns the problem of multicollinearity. When a number of descriptors are included in the analysis, correlation among them will inevitably arise, and it will therefore be more difficult to discriminate among their effects. There is a remarkably widespread misunderstanding of the effects of multicollinearity in a multiple regression: many people believe that the presence of multicollinearity results in bias in estimated coefficients, or estimated standard errors, or both. This is not true. The regression provides an unbiased indication of the coefficients for (partial derivatives with respect to) the descriptors and of the degree to which these are accurately estimated in spite of the correlation with other descriptors. The $t$-statistics for the estimated coefficients provide a reliable test of the wisdom with which descriptors were constructed. With this in mind, we were not excessively afraid of multicollinearity.

On the other hand, when two descriptors are highly correlated, it becomes difficult to distinguish their effects; consequently, every effort was made to anticipate correlations in advance and to construct welldifferentiated descriptors that would exhibit significant variation relative to one another. For instance, instead of employing a multitude of financial ratios, we designed one or two that we believed were the best measures of that aspect of financial condition. When we employed two measures of the same conceptual variable, it was always for one of two 

Section

\begin{tabular}{|c|c|c|c|c|c|}
\hline Descriptor & $\begin{array}{l}\text { Minimum } \\
\text { Value }\end{array}$ & $\begin{array}{l}\text { Equal- } \\
\text { Weighted } \\
\text { Mean }\end{array}$ & $\begin{array}{l}\text { Maximum } \\
\text { Value }\end{array}$ & $\begin{array}{l}\text { Capitali- } \\
\text { zation- } \\
\text { Weighted } \\
\text { Mean }\end{array}$ & $\begin{array}{l}\text { Standard } \\
\text { Deviation }\end{array}$ \\
\hline 1 NCMLDA & -.1475 & .1460 & .4120 & .1239 & .0844 \\
\hline 2 COMLNA & .1057 & .2333 & .3837 & .2298 & .0557 \\
\hline 3 NCNLDA & -.6350 & -.2385 & .1193 & -.3405 & .1259 \\
\hline 4 CONLNA & .0089 & .1130 & .2454 & .0744 & .0535 \\
\hline 5 MUNIBA & .0156 & .0891 & .2267 & .0691 & .0446 \\
\hline 6 RELNSA & .0061 & .1249 & .4460 & .0883 & .0701 \\
\hline 7 ISECTA & .0537 & .2017 & .3648 & .1576 & .0727 \\
\hline 8 TRDASA & 0 & .0073 & .0495 & .0102 & .0102 \\
\hline 9 CONTDA & 0 & .1456 & .5266 & .0960 & .1435 \\
\hline 10 DEMNDA & 0 & .3023 & .4522 & .2603 & .0695 \\
\hline $11 \mathrm{NFFBA}$ & -.1106 & .0227 & .1874 & .0338 & .0518 \\
\hline 12 FORDPA & 0 & .0747 & .4860 & .2007 & .1054 \\
\hline 13 SAVEDA & 0 & .1357 & .4891 & .0899 & .1295 \\
\hline 14 TBORA & .0011 & .1131 & .3119 & .1220 & .0610 \\
\hline 15 TCAPA & .0441 & .0785 & .1543 & .0698 & .0170 \\
\hline 16 TIMEDA & 0 & .3513 & .6782 & .4322 & .1329 \\
\hline 17. ATOLB & 8.5768 & 16.8619 & 29.1167 & 19.4978 & 4.0698 \\
\hline 18 BLEV & 1.0000 & 1.1357 & 3.5593 & 1.0957 & .2510 \\
\hline 19 DILU & .7135 & .9803 & 1.0000 & .9813 & .0432 \\
\hline 20 DTOA & 0 & .0533 & .2001 & .0663 & .0451 \\
\hline 21 кMTMN & 18.00 & 129.45 & 199.00 & 109.35 & 34.71 \\
\hline 22 kMTUS & 7.00 & 25.84 & 50.00 & 26.40 & 8.83 \\
\hline 23 KPDEP & -.0530 & -.0044 & .0424 & -.0071 & .0165 \\
\hline 24 RLTLTL & .2305 & 6.9374 & 18.3476 & 10.2528 & 3.5803 \\
\hline $25 \operatorname{ATAX}$ & 0 & .1945 & .4367 & .2767 & .1113 \\
\hline 26 FFMKT & 0 & .0425 & .1811 & .0359 & .0391 \\
\hline 27 FLO1 & -.0503 & .5694 & 2.6196 & .5017 & .6807 \\
\hline 28 FRGNO & 0 & .0009 & .0390 & .0071 & .0048 \\
\hline 29 PAY1 & .1453 & .4405 & .6564 & .4245 & .0925 \\
\hline $30 \mathrm{PNCV}$ & 0 & .0667 & .8997 & .0205 & .1745 \\
\hline 31 SALTOR & .0950 & .2063 & .3644 & .1723 & .0456 \\
\hline 32 TRDVRA & 0 & .0295 & .3160 & .0313 & .0485 \\
\hline 33 VCAP & .0284 & .1029 & .2146 & .1052 & .0357 \\
\hline 34 VERN & .0550 & .3014 & 2.4219 & .2114 & .4270 \\
\hline 35 VFLO & .0076 & .2274 & .8744 & .2863 & .1062 \\
\hline 36 ABET & 0 & .0468 & .4109 & .0200 & .0874 \\
\hline 37 CUTD & 0 & .0271 & .4870 & .0055 & .0932 \\
\hline 38 DELE & -2.0000 & .0753 & 2.0000 & .0356 & .5295 \\
\hline 39 DMNE & 0 & .0407 & 1.0 & .0048 & .1983 \\
\hline 40 MRGIN & -.0390 & .0817 & .1733 & .0830 & .0404 \\
\hline 41 REVENA & .0321 & .0699 & .0942 & .0680 & .0076 \\
\hline 42 ROEQ & -.0732 & .1192 & .2201 & .1378 & .0377 \\
\hline
\end{tabular}


Table 16.2 (continued)

\begin{tabular}{|c|c|c|c|c|c|}
\hline Descriptor & $\begin{array}{l}\text { Minimum } \\
\text { Value }\end{array}$ & $\begin{array}{l}\text { Equal- } \\
\text { Weighted } \\
\text { Mean }\end{array}$ & $\begin{array}{l}\text { Maximum } \\
\text { Value }\end{array}$ & $\begin{array}{l}\text { Capitali- } \\
\text { zation- } \\
\text { Weighted } \\
\text { Mean }\end{array}$ & $\begin{array}{l}\text { Standard } \\
\text { Deviation }\end{array}$ \\
\hline 43 AGRO & -.0544 & .0760 & .3186 & .1031 & .0537 \\
\hline 44 DMS5 & 0 & .9593 & 1.0 & .9849 & .1983 \\
\hline 45 EGRO & -.3415 & -.0068 & .2059 & .0643 & .1336 \\
\hline 46 OFFEX & -.8224 & .0880 & .9950 & .0890 & .3342 \\
\hline 47 RSKLGO & -.2488 & .0084 & .2658 & .0275 & .0889 \\
\hline 48 ASSI & 6.5201 & 7.8866 & 10.9728 & 9.1057 & .9347 \\
\hline 49 MKTS & 59.05 & 392.32 & 4844.75 & 1494.70 & 723.91 \\
\hline 50 KBET & .1684 & .9593 & 1.9306 & 1.0873 & .3133 \\
\hline 51 BTSQ & .0284 & 1.0129 & 3.1565 & 1.2484 & .6166 \\
\hline 52 HSIG & .0252 & .0709 & .1247 & .0684 & .0185 \\
\hline $53 \mathrm{SGSQ}$ & .0006 & .0053 & .0135 & .0048 & .0027 \\
\hline 54 BS & .0796 & .2573 & .4235 & .2705 & .0633 \\
\hline 55 BADJ & -.1787 & -.0073 & .2523 & .0186 & .0773 \\
\hline 56 LPRI & 1.3218 & 3.0758 & 4.0254 & 3.3659 & .5323 \\
\hline 57 RSTR & -.5275 & .0231 & .3881 & -.0371 & .1612 \\
\hline 58 TREC & 0 & .0644 & .2927 & .0253 & .0744 \\
\hline 59 ATOLM & 9.5411 & 21.7743 & 47.3130 & 19.1801 & 9.1119 \\
\hline $60 \mathrm{BBET}$ & -.3395 & .1704 & .2769 & .1584 & .0671 \\
\hline 61 BTOP & .5498 & 1.3745 & 4.2768 & 1.0333 & .5760 \\
\hline $62 \mathrm{CAPT}$ & 14.3343 & 18.6962 & 22.2060 & 20.1191 & 1.0909 \\
\hline 63 DMYL & 0 & .0163 & 1.0 & .0009 & .1270 \\
\hline 64 ENTP & -3.3691 & .0818 & .2043 & .1125 & .3214 \\
\hline 65 ETOP & -.1867 & .1126 & .2090 & .1109 & .0618 \\
\hline 66 ETP5 & -.0088 & .1215 & .2023 & .1099 & .0367 \\
\hline $67 \mathrm{LQU}$ & -3.4624 & 1.5571 & 11.7263 & 1.9314 & 2.0686 \\
\hline 68 MLEV & 1.0000 & 1.2283 & 8.7087 & 1.1119 & .7082 \\
\hline 69 ECAP & 1.68 & 247.27 & 2577.91 & 927.15 & 411.69 \\
\hline 70 PTEQ & .0566 & .4358 & 1.3210 & .2711 & .2861 \\
\hline 71 YILD & 0 & .0531 & .0893 & .0444 & .0185 \\
\hline 72 YL.D5 & 0 & .0533 & .0995 & .0447 & .0188 \\
\hline 73 DRMNY & 9 & \multirow{6}{*}{\multicolumn{4}{|c|}{ Number of banks in each group }} \\
\hline 74 DRMON & 8 & & & & \\
\hline 75 DRSE & 29 & & & & \\
\hline 76 DRMW & 31 & & & & \\
\hline 77 DRsw & 13 & & & & \\
\hline 78 DRWC & 11 & & & & \\
\hline
\end{tabular}


reasons: sometimes both measures were subject to independent measurement errors, so that a weighted average of the two would be a more accurate estimator of the underlying concept than either separately; sometimes we were uncertain a priori which would be the better descriptor, recognizing that the two definitions were clearly substitutes for one another, and so we relied on the regression to discriminate between the two. The latter was the case for four descriptors (NCMLDA, NCNLDA, FLO1, PAY1). We used two definitions of each in the early stages and chose the best for the subsequent analysis.

3. The third principle was the requirement that each descriptor be valid across the entire cross section of banks. We were careful to operationalize our concepts through formulas that would be applicable to all cases. This aspect of our approach is best explained by illustrating its violation. In many studies, the chosen measure of earnings growth was useless when earnings were negative, with the result that all banks that had had negative earnings had to be excluded from the sample; in contrast, we never deleted an observation because a computational formula failed. As another instance of this principle, we employed only descriptors for which data were available for the majority of our sample.

4. A fourth principle was the search for robust formulas-in other words, for formulas that yielded reasonable descriptors for the conceptual variable regardless of the peculiar historical circumstances of the bank. This principle led in many cases to the use of five-year averages, to smoothed values, or to the need for a truncation rule that wiped out otherwise extreme values. In general, the goal was a formula that would always produce a value that seemed reasonable when the raw data were examined.

5. A fifth principle was a variant of Occam's razor: When alternative formulas for a conceptual variable were available, and the difference in their validity was expected to be small, we chose the formula that was more familiar to professionals in the field of finance.

6. A sixth principle was that the descriptors were transformed to obtain a model that was linear. We attempted to transform descriptors and to draw in extreme outliers, so that the relationship between risk and the descriptors would be linear. In all cases, histograms of the descriptors were constructed to verify that the descriptor's range was appropriate and that a linear relationship would make sense. Only in the cases of historical beta, historical sigma, and capitalization (descriptors that have important predictive content for risk, and for which the relationship is clearly nonlinear) did we include several functions of the variables as descriptors in order to obtain a nonlinear relationship.

7. A seventh and final principle was that we relied on a priori judgment wherever possible. In other words, we attempted to select the descriptors on the basis of economic theory and in conformity with the above- 
mentioned principles. Then we computed the values of each descriptor and examined them across a sample population to check for robustness and reasonableness. We examined the correlation matrix among descriptors and redefined them in a few cases where extreme correlations showed up. Only after this was done were the descriptors introduced into a regression where any aspect of risk was the dependent variable.

Another important issue concerns the treatment of extreme or outlying values of the descriptors. No matter how robust a formula is, a few extraordinarily low or high values for banks in peculiar circumstances may be generated. Sometimes the formula is so constructed that these values represent equally extreme states of the underlying characteristic. In this case the descriptor should be left as it is. But in other cases the extreme values exaggerate the differences between the bank and the population of banks with ordinary values. In this case it is appropriate to "pull in" the extreme value toward a more ordinary one. The reasoning behind this is that the bank really does not differ much from the group of banks at the boundary of the commonly observed region for the descriptor, so that the descriptor for this bank should be set equal to the value at the boundary.

This can be done by defining a lower and upper bound for the descriptor and redefining all values that fall outside the bounds to equal the bounds. Any value that falls below the lower bound is transformed to equal the lower bound; any value that is above the upper bound is transformed to equal the upper bound. This process may be called "Windsorizing" or, to use a more familiar but less specific term, truncation. For the majority of descriptors, the truncation criteria have been expressed in terms of multiples of the cross-sectional standard deviation among all banks. This means that values falling more than some number (five, for example) of cross-sectional standard deviations above the capitalization-weighted mean will be set equal to that upper bound.

The outcome of all this is that the descriptors seem to be fairly satisfactory. First, they appear to be meaningful in comparison across the full range of normal banks; this applies both within a cross section and in comparisons of the same bank over time. Second, the outlying cases have tended to coincide with a difficult period for the bank in question. Thus the descriptors have proved to be accurate indicators of extreme risk.

Some descriptors that may indicate banks with potential or clear-cut problems are listed in table 16.3, and the banks so indicated (as of June 1977) are listed in table 16.4. In general, these outliers are quite far from the mean - the values for ROEQ, ENTP, ETOP, and MLEV are, for example, ten standard deviations. Two variables, DMNE and DMYL, are dummy variables; the outliers here are values of one. It is interesting to note that, of all twelve descriptors, five are calculated from only accounting data (BLEV, PNCV, VERN, DMNE, ROEQ), one is a descriptor of market price 
Table 16.3

Descriptor Outliers from the June 1977 Cross Section

\begin{tabular}{lll}
\hline \multicolumn{1}{c}{ Descriptor } & $\begin{array}{l}\text { Outlier } \\
\text { Direction }\end{array}$ & $\begin{array}{l}\text { Outlying } \\
\text { Banks }^{\mathrm{a}}\end{array}$ \\
\hline $18 \mathrm{BLEV}$ - leverage at book & High & 72 \\
$30 \mathrm{PNCV}$ - probability of noncoverage & High & $28,66,72,99$ \\
34 VERN - variance of earnings & High & $28,57,66$ \\
39 DMNE - dummy, negligible earnings & High & $24,57,66,72,87$ \\
42 ROEQ - income/equity & Low & 72 \\
52 HSIG - historical sigma & High & 72 \\
61 BTOP - book/price & High & 72 \\
63 DMYL - dummy, low yield & High & 72,99 \\
64 ENTP - normalized earnings/price & Low & 72 \\
65 ETOP - earnings/price & Low & 72 \\
66 ETP5 - earnings/price, five years & Low & 66,72 \\
68 MLEV - leverage at market & High & 72 \\
\hline
\end{tabular}

${ }^{\text {aS }}$ See table 16.4 for bank identification.

${ }^{b} \mathrm{~A}$ value of one.

variability (HSIG), and the remaining six utilize both accounting data and the market valuations of common stock. We feel that these findings are potentially important and deserve further study.

\subsection{Procedure}

Our primary data source is the COMPUSTAT bank tapes, which contain data on 124 large United States banks. Both the annual and the quarterly tapes were used, although the only information taken from the latter was the monthly closing price of the common stock. A few additional items were drawn from the Keefe Bank Manuals. Because of the pattern of data availability, the present study begins in March 1969 and continues through June 1977; this gives us a total of 11,219 data points, each being a monthly observation of a bank.

The first step is to compute, for each of the thirty-four quarters, the value of each descriptor for each bank in the sample, as it could have been computed at the beginning of that quarter. It is important to note that

Table 16.4

Bank Identification

\begin{tabular}{lll}
\hline Number & Region & Name \\
\hline 24 & Eastern & First Empire State Corporation \\
28 & Eastern & Hartford National Corporation \\
57 & Southeastern & Flagship Banks \\
66 & Southeastern & Union Planters Corporation \\
72 & Midwestern & Bank of Commonwealth, Detroit \\
87 & Midwestern & Indiana National Corporation \\
99 & Midwestern & Union Commerce Corporation \\
\hline
\end{tabular}


data are used for any quarter only if they would have been available at the start of that quarter. Data related to the stock market are presumed to be published immediately. Annual accounting data are not presumed to become available until four months after the end of the fiscal year; this allows for the ninety-day reporting delay and thirty more days for the data to be assembled into machine-readable form. This procedure ensures that an observer could actually have computed these descriptors at the start of each quarter.

The sample of banks for any quarter is made up of all banks; any descriptor that is unavailable for a particular bank is assumed to be equal to the average value of that descriptor for that cross section. For each of the three months in the quarter, the monthly subsample is made up of all banks for which stock price returns in that month are available. These stock price returns are analyzed in relation to the descriptors computed as of the beginning of the quarter. Thus, three monthly samples are predicted with each set of descriptors, in conformity with a prediction rule that is revised quarterly and is based upon previously published information.

The model and the estimation procedure used are described in detail in the Appendix. Several interesting points that should be noted are:

1. The estimation approach is iterative, in that the prediction rule for beta is estimated first; this is then used to define the dependent variable for the sigma prediction rule regression.

2. Generalized least squares is used to account for heteroskedasticity. The resulting prediction rules are more statistically efficient.

3. The prediction rules are estimated simultaneously for all individual banks in all time periods, through a pooled time-series, cross-sectional regression.

4. The beta prediction rule is conditional upon the market return (the CRSP RETV index), and the sigma prediction rule is conditional upon the typical cross-sectional standard deviation of residual return in any given month.

The study adhered strictly to the principles of experimental design. All procedures were specified in advance of examining the returns to be predicted. This was done to ensure that the study would be selfvalidating. Otherwise there would be no assurance that the results were likely to persist into the future.

\subsection{Empirical Results}

As a preliminary to the multiple-regression results, table 16.5 reports the simple regressions of investment risk on each of the descriptors. The predictive content of each descriptor, taken separately, is given for beta and for sigma. Since the multiple regression is not used, the predictive 


\begin{tabular}{|c|c|c|c|c|c|c|}
\hline \multirow[b]{2}{*}{ Descriptor } & \multicolumn{3}{|c|}{ Prediction of Beta } & \multicolumn{3}{|c|}{ Prediction of Sigma } \\
\hline & $\begin{array}{l}\text { Coef- } \\
\text { ficient }^{a}\end{array}$ & $\begin{array}{l}t \text {-Sta- } \\
\text { tistic }^{b}\end{array}$ & $\begin{array}{l}\text { Order of } \\
\text { Impor- } \\
\text { tance }^{c}\end{array}$ & $\begin{array}{l}\text { Coef- } \\
\text { ficient }^{\text {a }}\end{array}$ & $\begin{array}{l}t \text {-Sta } \\
\text { tistic }^{b}\end{array}$ & $\begin{array}{l}\text { Order of } \\
\text { Impor- } \\
\text { tance }^{c}\end{array}$ \\
\hline 1 NCMLDA & -.441 & -2.92 & 41 & -.029 & -.31 & 71 \\
\hline 2 COMLNA & -.211 & -1.14 & 60 & -.228 & -1.97 & 50 \\
\hline 3 NCNLDA & -.221 & -2.02 & 50 & .122 & 1.75 & 51 \\
\hline 4 CONLNA & -.211 & -.88 & 64 & .626 & 4.15 & 28 \\
\hline 5 MUNIBA & -1.187 & -3.77 & 32 & -.726 & -3.64 & 32 \\
\hline 6 RELNSA & -.422 & -2.02 & 49 & .223 & 1.68 & 53 \\
\hline 7 ISECTA & -1.569 & -7.45 & 12 & -.351 & -2.63 & 44 \\
\hline 8 TRDASA & .406 & .63 & 71 & -1.090 & -2.65 & 43 \\
\hline 9 CONTDA & .185 & 1.67 & 53 & -.063 & -.90 & 63 \\
\hline 10 DEMNDA & -.905 & -7.47 & 11 & -.294 & -3.73 & 31 \\
\hline 11 NFFBA & 1.512 & .5 .17 & 26 & -.0051 & -.03 & 78 \\
\hline 12 FORDPA & 1.139 & 7.18 & 14 & -.030 & -.30 & 72 \\
\hline 13 SAVEDA & .121 & 1.04 & 62 & -.087 & -1.19 & 59 \\
\hline 14 TBORA & 1.093 & 4.86 & 28 & -.011 & -.07 & 77 \\
\hline 15 TCAPA & -4.689 & -5.59 & 21 & -1.898 & -3.61 & 33 \\
\hline 16 TMEDA & .207 & 2.20 & 45 & .162 & 2.67 & 42 \\
\hline 17 ATOLB & .026 & 8.12 & $9^{*}$ & .014 & 6.47 & 19 \\
\hline 18 BLEV & .208 & 3.75 & 33 & .302 & 7.84 & $8^{*}$ \\
\hline 19 DILU & -.739 & -1.99 & 51 & .719 & 3.14 & 40 \\
\hline 20 DTOA & 1.583 & 5.22 & 25 & .179 & .90 & 64 \\
\hline 21 KMTMN & -.00037 & -.81 & 65 & .00031 & 1.06 & 62 \\
\hline 22 кмтUs & -.0058 & -3.74 & 34 & -.00043 & -.42 & 69 \\
\hline 23 KPDEP & .483 & 1.22 & 57 & -.475 & -2.04 & 48 \\
\hline 24 RLTLTL & .022 & 5.72 & 20 & .0097 & 3.85 & 30 \\
\hline 25 ATAX & -.185 & -1.24 & 56 & -.325 & -3.59 & 34 \\
\hline .26 FFMKT & -.039 & -.10 & 78 & -.468 & -2.00 & 49 \\
\hline 27 FLo1 & -.038 & -2.63 & 44 & -.046 & -5.08 & 26 \\
\hline 28 FRGNO & 6.401 & 3.17 & 37 & -2.407 & -2.17 & 46 \\
\hline 29 PAYI & -.214 & -1.40 & 55 & .0077 & .08 & 76 \\
\hline $30 \mathrm{PNCV}$ & -.303 & -.69 & 66 & 1.282 & 6.44 & 20 \\
\hline 31 SALTOR & .040 & .16 & 77 & .522 & 3.35 & 36 \\
\hline 32 TRDVRA & .139 & .28 & 75 & -.421 & -1.49 & 54 \\
\hline 33 VCAP & 1.443 & 4.80 & 29 & .737 & 3.89 & 29 \\
\hline 34 VERN & .134 & 1.06 & 61 & .958 & 13.21 & $3^{*}$ \\
\hline 35 VFLO & .542 & 3.48 & 36 & .657 & 6.87 & 17 \\
\hline 36 ABET & -.520 & -1.14 & 59 & 2.006 & 8.03 & $7^{*}$ \\
\hline 37 CUTD & 1.293 & 2.05 & 48 & 2.076 & 5.60 & 25 \\
\hline 38 DELE & .204 & 2.98 & 40 & -.116 & -3.18 & 39 \\
\hline 39 DMNE & -.147 & -.90 & 63 & .589 & 6.02 & 23 \\
\hline 40 MRGIN & -1.789 & -5.79 & 19 & -1.454 & -7.57 & 11 \\
\hline 41 REVENA & .274 & .26 & 76 & 2.232 & 3.37 & 35 \\
\hline 42 ROEQ & 2.445 & 4.05 & 31 & -.095 & -.24 & 73 \\
\hline
\end{tabular}




\begin{tabular}{|c|c|c|c|c|c|c|}
\hline \multirow[b]{2}{*}{ Descriptor } & \multicolumn{3}{|c|}{ Prediction of Beta } & \multicolumn{3}{|c|}{ Prediction of Sigma } \\
\hline & $\begin{array}{l}\text { Coef- } \\
\text { ficient }^{a}\end{array}$ & $\begin{array}{l}t \text {-Sta- } \\
\text { tistic }^{b}\end{array}$ & $\begin{array}{l}\text { Order of } \\
\text { Impor- } \\
\text { tance }^{c}\end{array}$ & $\begin{array}{l}\text { Coef- } \\
\text { ficient }\end{array}$ & $\begin{array}{l}t \text {-Sta- } \\
\text { tistic }\end{array}$ & $\begin{array}{l}\text { Order of } \\
\text { Impor- } \\
\text { tance }^{\circ}\end{array}$ \\
\hline 43 AGRO & 2.162 & 8.33 & $8^{*}$ & 1.305 & 7.49 & 13 \\
\hline 44 DMS5 & .174 & 4.99 & 27 & -.031 & -1.34 & 56 \\
\hline 45 EGRO & .145 & .66 & 67 & -.285 & -2.15 & 47 \\
\hline 46 OFFEX & .019 & .44 & 74 & -.014 & -.48 & 68 \\
\hline 47 RSKLGO & .148 & 2.09 & 47 & .028 & .58 & 67 \\
\hline 48 ASSI & .125 & 9.29 & $3^{*}$ & -.020 & -2.39 & 45 \\
\hline 49 MKTs & .00020 & 6.43 & 16 & -.000014 & -.77 & 65 \\
\hline 50 HВET & .444 & 9.97 & $1^{*}$ & .217 & 7.64 & $10^{*}$ \\
\hline 51 BTSQ & .269 & 9.05 & $4^{*}$ & .134 & 7.33 & 14 \\
\hline 52 HSIG & 6.778 & 6.72 & 15 & 8.844 & 14.44 & $1^{*}$ \\
\hline 53 SGSQ & 48.575 & 5.87 & 18 & 68.098 & 13.84 & $2^{*}$ \\
\hline 54 BS & 2.325 & 9.96 & $2^{*}$ & 1.594 & 11.00 & $4^{*}$ \\
\hline 55 BADI & 1.015 & 5.48 & 23 & .151 & 1.22 & 58 \\
\hline 56 LPRI & -.068 & -2.84 & 42 & -.161 & -10.12 & $5^{*}$ \\
\hline 57 RSTR & -.411 & -8.85 & $5^{*}$ & -.039 & -1.13 & 61 \\
\hline 58 TREC & -.382 & -7.23 & 13 & .025 & .74 & 66 \\
\hline 59 ATOLM & .0046 & 3.15 & 38 & .0033 & 3.26 & 37 \\
\hline $60 \mathrm{BBET}$ & -1.874 & -5.92 & 17 & -.921 & -4.46 & 27 \\
\hline 61 BTOP & -.013 & -.49 & 73 & .0059 & .32 & 70 \\
\hline 62 CAPT & .112 & 8.45 & $7^{*}$ & -.027 & -3.21 & 38 \\
\hline 63 DMYL & .332 & 1.58 & 54 & 1.068 & 7.55 & 12 \\
\hline 64 ENTP & .141 & .61 & 72 & -1.059 & -6.89 & 16 \\
\hline 65 ETOP & .292 & 1.18 & 58 & -1.159 & -6.92 & 15 \\
\hline 66 ЕTP5 & -4.230 & -7.96 & $10^{*}$ & -2.418 & -7.81 & $9^{*}$ \\
\hline $67 \mathrm{LIQU}$ & .013 & 1.77 & 52 & -.0059 & -1.18 & 60 \\
\hline 68 MLEV & .131 & 2.80 & 43 & .268 & 8.65 & $6^{*}$ \\
\hline 69 ECAP & .00019 & 5.51 & 22 & -.000032 & -1.46 & 55 \\
\hline 70 PTEQ & .120 & 2.17 & 46 & .245 & 6.63 & 18 \\
\hline 71 YILD & -.346 & -.63 & 70 & -.077 & -.21 & 75 \\
\hline 72 YLD5 & -9.248 & -8.58 & $6^{*}$ & -3.741 & -5.91 & 24 \\
\hline 73 DRMNY & .200 & 4.30 & 30 & -.050 & -1.68 & 52 \\
\hline 74 DRMON & .030 & .65 & 68 & -.0064 & -.21 & 74 \\
\hline 75 DRSE & .097 & 3.00 & 39 & .129 & 6.22 & 22 \\
\hline 76 DRMW & -.152 & -5.41 & 24 & -.112 & -6.28 & 21 \\
\hline 77 DRSW & -.027 & -.64 & 69 & .033 & 1.26 & 57 \\
\hline 78 DRWC & .175 & 3.73 & 35 & .092 & 3.02 & 41 \\
\hline
\end{tabular}

${ }^{a}$ For beta, the coefficient gives the adjustment to predicted beta for a unit change in the descriptor. For sigma, the coefficient gives the adjustment to the relative value of sigma (i.e., sigma $\div$ cross-sectional average sigma) for a unit change in the descriptor.

For purposes of interpretation, it is also useful to know the change in the dependent variable implied by a one-standard-deviation shift in the descriptor, i.e., the coefficient with respect to a normalized descriptor. This adjusted coefficient is obtained by multiplying the reported coefficient by the descriptor's standard deviation, which is given in column 5 of table 16.2 . 
content of each descriptor includes its role as a surrogate for all other descriptors as well as its own intrinsic relevance.

The $t$-statistics for the relationships and the relative order of importance of the descriptors are interesting. For beta, the single most powerful predictor is HBET, the historical estimate of beta. The second- and fourth-best predictors are BS, the geometric average of the historical estimates of beta and sigma, and BTSQ, the square of HBET. The third most effective is ASSI, which measures the total assets of the bank: the larger the bank, the greater its beta. The fifth most important is the "relative strength" (RSTR) of the bank in the preceding year: the better the past market performance of the common stock, the lower the expected beta. Sixth is YLD5, the "normal" dividend yield. Seventh is total equity (market) capitalization (CAPT). Eighth is AGRo, the asset growth rate: the higher this growth rate, the higher the bank's beta. Next is a measure of leverage, the ratio of total assets to long-term liabilities or capital, valued at book (ATOLB). Tenth is ETP5, the bank's "typical" earnings/price ratio: the higher this ratio (or the lower the price/earnings ratio), the lower the bank's beta.

For residual standard deviation, or sigma, the two most important descriptors are measures related to historical sigma (HSIG, SGSQ). The third is the historical variability of earnings (VERN), while the fourth is related to historical sigma and beta (BS). Fifth is the logarithm of the price of the common stock (LPRI): the higher the price, the lower is sigma. Two different measures of leverage in the capital structure (MLEV and BLEV) are sixth and eighth in importance: the greater the leverage - whether calculated using book or market value of equity-the greater the residual variance. Seventh is a measure of "accounting beta" (ABET), and ninth is ETP5: the higher this ratio, the lower is sigma. Finally, historical beta (HBET) is tenth.

It is significant that those descriptors with the highest predictive content for beta are not the same as those for sigma; only three (HBET, ETP5, Bs) are among the top ten for both beta and sigma. Thus, not only are systematic risk and residuai risk fundamentally different aspects of the overall risk of a bank, but they are, in addition, determined by different aspects of the bank's operational characteristics.

Table 16.6 reports the results of regressions for beta, using descriptors of assets and liabilities. Using the simplest model of the investment risk of

This is the $t$-statistic for the simple GLS regression in which the descriptor is the only information used to predict risk, with 11,217 degrees of freedom. The critical point for the 99 percent confidence level is 2.58 . The larger the absolute value of the $t$-statistic, the larger is the predictive content of this descriptor when used alone. The $R^{2}$ (coefficient of determination) achieved by each descriptor alone is proportional to the squared $t$-statistic.

'This is the rank of the descriptor, among all descriptors, in terms of explanatory power, with 1 being the highest. The asterisks denote the top ten. 
a portfolio of assets and liabilities, the systematic risk of the net portfolio (excluding capital accounts) is a linear function of the proportions in asset and liability categories, with coefficients that reflect the systematic risks of the various categories. The systematic risk of the shareholders' equity

Table 16.6

Asset/Liability Descriptor Regressions for Beta

\begin{tabular}{|c|c|c|c|c|}
\hline Descriptor & $\begin{array}{l}\text { Assets } \\
\text { Only }\end{array}$ & $\begin{array}{l}\text { Liabil- } \\
\text { ities } \\
\text { Only }\end{array}$ & $\begin{array}{l}\text { All Asset/ } \\
\text { Liability } \\
\text { Descriptors }\end{array}$ & $\begin{array}{l}\text { With Net } \\
\text { Asset/ } \\
\text { Liability } \\
\text { Descriptors }\end{array}$ \\
\hline Constant & $\begin{array}{c}.278 \\
(.182)\end{array}$ & $\begin{array}{c}.658 \\
(.239)\end{array}$ & $\begin{array}{l}1.013 \\
(.285)\end{array}$ & $\begin{array}{c}.731 \\
(.213)\end{array}$ \\
\hline 1 NCMLDA & & & & $\begin{array}{c}.185 \\
(.187)\end{array}$ \\
\hline 2 COMLNA & $\begin{array}{c}-.381 \\
(.218)\end{array}$ & & $\begin{array}{c}-.355 \\
(.251)\end{array}$ & \\
\hline 3 NCNLDA & & & & $\begin{array}{c}.302 \\
(.135)\end{array}$ \\
\hline 4 CONLNA & $\begin{array}{c}.612 \\
(.292)\end{array}$ & & $\begin{array}{c}.278 \\
(.308)\end{array}$ & \\
\hline 5 MUNIBA & $\begin{array}{l}1.764 \\
(.514)\end{array}$ & & $\begin{array}{l}1.724 \\
(.537)\end{array}$ & $\begin{array}{l}1.698 \\
(.528)\end{array}$ \\
\hline 6 RELNSA & $\begin{array}{c}-.367 \\
(.239)\end{array}$ & & $\begin{array}{c}-.737 \\
(.295)\end{array}$ & \\
\hline 7 ISECTA & $\begin{array}{r}-1.900 \\
\quad(.364)\end{array}$ & & $\begin{array}{r}-1.955 \\
(.412)\end{array}$ & $\begin{array}{r}-1.708 \\
\quad(.400)\end{array}$ \\
\hline 8 TRDASA & $\begin{array}{c}-.983 \\
(.671)\end{array}$ & & $\begin{array}{r}-1.538 \\
(.711)\end{array}$ & $\begin{array}{r}-1.378 \\
(.703)\end{array}$ \\
\hline $9 \mathrm{CONTDA}$ & & $\begin{array}{l}1.505 \\
(.579)\end{array}$ & $\begin{array}{l}1.394 \\
(.585)\end{array}$ & \\
\hline 10 DEMNDA & & $\begin{array}{c}-.658 \\
(.176)\end{array}$ & $\begin{array}{c}-.645 \\
(.179)\end{array}$ & $\begin{array}{c}-.670 \\
(.146)\end{array}$ \\
\hline 11 NFFBA & & $\begin{array}{c}.606 \\
(.327)\end{array}$ & $\begin{array}{c}.849 \\
(.337)\end{array}$ & $\begin{array}{c}.850 \\
(.348)\end{array}$ \\
\hline 12 FORDPA & & $\begin{array}{c}.092 \\
(.237)\end{array}$ & $\begin{array}{c}-.442 \\
(.295)\end{array}$ & $\begin{array}{c}-.081 \\
(.263)\end{array}$ \\
\hline 13 SAVEDA & & $\begin{array}{c}-.145 \\
(.624)\end{array}$ & $\begin{array}{r}.0010 \\
(.638)\end{array}$ & \\
\hline 14 TBORA & & $\begin{array}{c}.078 \\
(.285)\end{array}$ & $\begin{array}{c}-.342 \\
(.343)\end{array}$ & $\begin{array}{c}.010 \\
(.307)\end{array}$ \\
\hline $15 \mathrm{TCAPA}$ & & $\begin{array}{c}-1.949 \\
(1.009)\end{array}$ & $\begin{array}{c}-1.953 \\
(1.052)\end{array}$ & $\begin{array}{r}-1.400 \\
(.984)\end{array}$ \\
\hline 16 TIMEDA & & $\begin{array}{c}-.324 \\
(.170)\end{array}$ & $\begin{array}{c}-.111 \\
(.187)\end{array}$ & \\
\hline 48 ASSI & $\begin{array}{l}.109 \\
(.016)\end{array}$ & $\begin{array}{c}.086 \\
(.020)\end{array}$ & $\begin{array}{c}.085 \\
(.021)\end{array}$ & $\begin{array}{c}.083 \\
(.020)\end{array}$ \\
\hline
\end{tabular}

Note: The standard error of each coefficient is given in parentheses. 
is then obtained by multiplying portfolio systematic risk by the leverage ratio and is consequently a nonlinear (inverse) function of the proportion of long-term capital. However, for simplicity, we first estimated a model for beta as a linear function of asset and liability proportions. (The coefficient of the equity proportion in this equation can be interpreted as the first-order term in a Taylor expansion and is therefore expected to be negative.)

Relationships including asset and liability proportions as descriptors were estimated first alone, then with one added descriptor of the size of the institutions: AsSI, the logarithm of total assets. The total asset variable is highly significant: the coefficient is positive for beta and negative for sigma. The coefficients of asset and liability proportions generally change very little as AssI is brought into the regressions. The major exception is in the coefficient of foreign deposits (FORDPA), which is positive for beta and negative for sigma when ASSI is excluded and reverses sign in both cases when ASSI is brought into the regression. Clearly, the proportion of foreign deposits is a surrogate for bank size. The general insensitivity of other coefficients to inclusion of ASSI is a sign that multicollinearity is absent. To save space, the results are reported for only one set of regressions, those including ASsI.

The regressions for beta in table 16.6 are of the form predicted $\beta=$ constant $+b_{\text {ASSI }}$ (In [total assets])

$$
+\sum_{j=1}^{J} b_{j}\left(\frac{\text { dollars in asset/liability category } j}{\text { total assets }}\right)
$$

The regressions for sigma in table 16.7 are of the form $\frac{\text { predicted sigma }}{\text { average sigma }}$ $=$ constant $+\mathrm{s}_{A S S I}(\ln [$ total assets] $)$

$$
+\sum_{j=1}^{J} s_{j}\left(\frac{\text { dollars in asset/liability category } j}{\text { total assets }}\right)
$$

The asset categories and liability categories are mutually exclusive but not exhaustive. The coefficients $b_{j}$ (or $s_{j}$ ) are not the beta (or sigma) levels for the categories, but rather are adjustments to the otherwise normal beta (or sigma) for a bank owing to the category. The essential content of the results lies in the differences between any pair of coefficients $b_{i}$ and $b_{j}$ (or $s_{i}$ and $s_{j}$ ). If funds are moved from category $i$ to category $j$, the difference in coefficients gives the expected effect on risk. For example, if one-tenth of a bank's liabilities are shifted from net federal funds bor-. rowed (NFFBA) to demand deposits (DEMNDA), the effect on risk can be found by comparing the coefficients for these two categories. For beta, $b_{N F F B A}=.849$ and $b_{D E M N D A}=-.645$. The difference in beta is $(-.645)-(.845)=-1.494$. A shift of one-tenth of liabilities from 
NFFBA to DEMNDA would cause one-tenth of this change, or a reduction in beta by 0.1494 . For sigma, the difference is $1 / 10((-.563)$ $-(.239))=-.080$. This is interpreted as a reduction in residual standard deviation (sigma) equal to 0.080 (8.0 percent) of average sigma. Of course these computed values are only estimates, but the relatively small standard errors for the coefficients allow us to place some confidence in the results, as being representative of the sample period in which the model was estimated.

The first regression in table 16.6 predicts beta based upon asset proportions. Tax-exempt bonds (MUNIBA) and to a lesser degree consumer loans (CONLNA) are found to be high-beta categories, while investment securities other than tax-exempts (ISECTA) and the trading account (TRDASA) are found to be very low beta, and real estate loans (RELNSA) and commercial loans (COMLNA) are moderately low beta. The standard errors of the estimated coefficients are typically small relative to the estimated magnitudes.

The second regression includes liabilities only. Consumer time deposits other than passbook savings (CONTDA) is a high-beta category, and net federal funds borrowed (NFFBA, the excess of borrowing over lending on the federal funds market) is moderately high beta. Demand deposits (DEMNDA) are relatively low beta. Shareholders' equity (TCAPA) greatly reduces beta, as is to be expected.

The third regression brings in both assets and liabilities. When compared with the two previous regressions, there are no changes in sign among the assets and several changes in sign involving insignificant magnitudes in the liabilities. The stability of coefficients suggests that each group of variables is not an important surrogate for the opposite category.

The final regression uses alternative measures of the portfolio, which rely on net differences between asset and liability groups rather than the separate amounts in the categories. Net consumer lending (NCNLDA), for example, equals consumer lending (CONLNA) plus real estate loans (RELNSA) less passbook savings (SAVEDA) and consumer time (CONTDA). The original reasoning behind the definition of these net activities was that interest rate and liquidity risks of the paired asset and liability categories were similar, so that the net would be a parsimonious measure of exposure. As expected, the loss in explanatory power owing to replacement of asset/liability categories by the nets is relatively small (table 16.10 below). For consumer lending, the net category is bound to be overly simplistic, for it lumps together real estate loans, a very low-beta category, with consumer lending, a relatively high-beta category. It probably would have been better to net consumer lending (CONLNA) against consumer time deposits other than passbook (CONTDA) and to net real estate lending against passbook deposits. 
Table 16.7 reports the regressions for sigma. It is interesting to compare these regressions with the beta regressions. The sigma regressions are estimated with substantially greater accuracy: the typical standard error is about one-half as great as for beta. This generally occurs when the same data base is used to estimate systematic risk and residual risk,

Table $\mathbf{1 6 . 7}$

Asset/Liability Descriptor Regressions for Sigma

\begin{tabular}{|c|c|c|c|c|}
\hline Descriptor & $\begin{array}{l}\text { Assets } \\
\text { Only }\end{array}$ & $\begin{array}{l}\text { Liabil- } \\
\text { ities } \\
\text { Only }\end{array}$ & $\begin{array}{l}\text { All Asset/ } \\
\text { Liability } \\
\text { Descriptors }\end{array}$ & $\begin{array}{l}\text { With Net } \\
\text { Asset/ } \\
\text { Liability } \\
\text { Descriptors }\end{array}$ \\
\hline Constant & $\begin{array}{l}1.399 \\
(.118)\end{array}$ & $\begin{array}{l}2.043 \\
(.156)\end{array}$ & $\begin{array}{l}2.163 \\
(.184)\end{array}$ & $\begin{array}{l}2.104 \\
(.139)\end{array}$ \\
\hline 1 NCMLDA & & & & $\begin{array}{c}.035 \\
(.116)\end{array}$ \\
\hline 2 COMLNA & $\begin{array}{c}-.166 \\
(.135)\end{array}$ & & $\begin{array}{c}-.152 \\
(.157)\end{array}$ & \\
\hline 3 NCNLDA & & & & $\begin{array}{l}.176 \\
(.086)\end{array}$ \\
\hline 4 CONLNA & $\begin{array}{c}.579 \\
(.181)\end{array}$ & & $\begin{array}{c}.502 \\
(.190)\end{array}$ & \\
\hline 5 MUNIBA & $\begin{array}{c}-.904 \\
(.323)\end{array}$ & & $\begin{array}{c}-.657 \\
(.334)\end{array}$ & $\begin{array}{c}-.729 \\
(.329)\end{array}$ \\
\hline 6 RELNSA & $\begin{array}{c}-.015 \\
(.152)\end{array}$ & & $\begin{array}{c}-.243 \\
(.191)\end{array}$ & \\
\hline 7 ISECTA & $\begin{array}{c}-.368 \\
(.229)\end{array}$ & & $\begin{array}{c}-.459 \\
(.258)\end{array}$ & $\begin{array}{c}-.306 \\
(.247)\end{array}$ \\
\hline 8 TRDASA & $\begin{array}{r}-1.280 \\
(.424)\end{array}$ & & $\begin{array}{r}-1.362 \\
(.449)\end{array}$ & $\begin{array}{r}-1.356 \\
\quad(.445)\end{array}$ \\
\hline 9 CONTDA & & $\begin{array}{c}.176 \\
(.344)\end{array}$ & $\begin{array}{c}-.059 \\
(.349)\end{array}$ & \\
\hline 10 DEMNDA & & $\begin{array}{c}-.572 \\
(.117)\end{array}$ & $\begin{array}{c}-.562 \\
(.118)\end{array}$ & $\begin{array}{c}-.547 \\
(.094)\end{array}$ \\
\hline 11 NFFBA & & $\begin{array}{c}-.033 \\
(.216)\end{array}$ & $\begin{array}{c}.239 \\
(.225)\end{array}$ & $\begin{array}{l}.185 \\
(.225)\end{array}$ \\
\hline 12 FORDPA & & $\begin{array}{c}.121 \\
(.152)\end{array}$ & $\begin{array}{c}-.115 \\
(.190)\end{array}$ & $\begin{array}{c}.034 \\
(.168)\end{array}$ \\
\hline 13 SAVEDA & & $\begin{array}{c}-.246 \\
(.377)\end{array}$ & $\begin{array}{c}-.217 \\
(.388)\end{array}$ & \\
\hline 14 TBORA & & $\begin{array}{c}-.350 \\
(.189)\end{array}$ & $\begin{array}{c}-.540 \\
(.227)\end{array}$ & $\begin{array}{c}-.318 \\
(.201)\end{array}$ \\
\hline 15 TCAPA & & $\begin{array}{r}-3.367 \\
(.632)\end{array}$ & $\begin{array}{r}-2.665 \\
(.661)\end{array}$ & $\begin{array}{r}-2.439 \\
(.617)\end{array}$ \\
\hline 16 TIMEDA & & $\begin{array}{r}-.150 \\
(.114)\end{array}$ & $\begin{array}{c}-.116 \\
(.127)\end{array}$ & \\
\hline 48 ASSI & $\begin{array}{c}-.032 \\
(.010)\end{array}$ & $\begin{array}{c}-.065 \\
(.013)\end{array}$ & $\begin{array}{c}-.061 \\
(.014)\end{array}$ & $\begin{array}{c}-.069 \\
(.013)\end{array}$ \\
\hline
\end{tabular}

Note: The standard error of each coefficient is given in parentheses. 
because the data are more informative concerning residual risk (a variance) than concerning systematic risk (a covariance).

Comparison of the asset/liability regressions for the two aspects of risk is also instructive. Equity capital and demand deposits are in both cases the two most risk-reducing liabilities. Conversely, net federal funds borrowing is a major risk-enhancing liability in both. However, two liability categories differently affect beta and sigma: consumer time deposits (CONTDA) and foreign deposits (FORDPA) negligibly affect sigma, but each variable has a substantial estimated effect on beta. Foreign deposits are estimated as reducing beta, as is natural, since the covariance of their profitability with the economy might be expected to be low. Consumer time deposits are the highest-beta liability.

On the asset side, consumer lending (CONLNA) is a high-risk category in both cases; the trading account and investment securities (TRDASA, ISECTA) are the lowest and second or third lowest in risk in the two cases. The risk contributions of municipal bonds (MUNIBA) are opposite in the two cases: municipal bonds are a far higher risk as regards beta and a far lower risk as regards sigma.

The coefficient of asset size (ASsI) remains to be discussed. It is negative and virtually constant in all regressions for sigma and positive and virtually constant in all regressions for beta. The coefficient for beta is quite similar to the simple regression coefficient, but the coefficient for sigma is larger in magnitude than the simple.

Table 16.8 reports regressions including all fundamentals. In addition to those relating to asset and liability proportions and total assets, descriptors of asset ratios and of the operating characteristics and income statement of the bank are added. The coefficients of the first sixteen descriptors are directly comparable with the estimates in tables 16.6 and 16.7. The sign of an estimated effect that is significant in one or the other table never changes as a result of including the other fundamentals. The insensitivity of signs and magnitudes of estimated effects to the added fundamentals is another encouraging indication of low multicollinearity.

A number of descriptors of operating characteristics are significant in the prediction of residual risk, but only one is significant in the prediction of beta. Among the significant descriptors in prediction of residual risk, most signs are plausible: the higher the effective tax rate (ATAX), the lower the residual risk; the greater the ratio of average cash flow to liabilities (FLO1), the lower the residual risk; the greater the payout ratio (PAY1), the lower the residual risk; the greater the earnings variability (VERN), the higher the residual risk; and the greater covariability of earnings with economywide earnings (ABET), the higher the residual risk. However, one effect is puzzling: the greater the apparent probability that fixed charges will not be covered ( $\mathrm{PNCV}$ ), the lower is the predicted residual risk. Obviously, the reverse sign is the one to be expected. The simple regression coefficient was positive and highly significant. 
Table 16.8

Regressions with All Fundamentals, Including Descriptors

Dependent upon the Market Valuation of Common Stock

\begin{tabular}{|c|c|c|c|c|}
\hline \multirow[b]{2}{*}{ Descriptor } & \multicolumn{2}{|c|}{ Regressions for Beta } & \multicolumn{2}{|c|}{ Regressions for Sigma } \\
\hline & Selected & All & Selected & All \\
\hline Constant & -.868 & $-2.890^{*}$ & -.915 & $-1.737^{*}$ \\
\hline 1 NCMLDA & & .0055 & & -.111 \\
\hline 2 COMLNA & $-.776^{* *}$ & $-.869^{* *}$ & & -.381 \\
\hline 3 NCNLDA & & .123 & & -.0048 \\
\hline 4 CONLNA & & -.658 & & .041 \\
\hline 5 MUNIBA & & .421 & $-.810^{* *}$ & $-.915^{*}$ \\
\hline 6 RELNSA & -.382 & -.529 & & -.278 \\
\hline 7 ISECTA & $-1.080^{* * *}$ & $-1.426^{* *}$ & & -.447 \\
\hline 8 TRDASA & -1.234 & -1.384 & $-1.351^{* *}$ & $-1.331^{*}$ \\
\hline 9 CONTDA & .069 & .611 & $-.267^{*}$ & -.085 \\
\hline 10 DEMNDA & $-.988^{* * *}$ & $-.957^{* * *}$ & -.229 & -.242 \\
\hline 11 NFFBA & $.963^{*}$ & $1.011^{*}$ & & .227 \\
\hline 12 FORDPA & & .301 & .200 & .298 \\
\hline 13 SAVEDA & & .203 & & -.285 \\
\hline 14 TBORA & & 1.094 & & -.105 \\
\hline $15 \mathrm{TCAPA}$ & & -.258 & & .333 \\
\hline 16 TIMEDA & & $.799^{*}$ & & .110 \\
\hline 17 ATOLB & .012 & .025 & $.028^{* * *}$ & $.024^{*}$ \\
\hline $18 \mathrm{BLEV}$ & $.159^{*}$ & $.346^{*}$ & .036 & .103 \\
\hline 19 DILU & -.600 & -.528 & $.869^{* * *}$ & $873^{* * *}$ \\
\hline 20 DTOA & & -1.101 & & -.822 \\
\hline 21 кмтмN & & -.00029 & & -.00067 \\
\hline 22 кMтUS & $-.0041^{*}$ & -.0035 & & -.00056 \\
\hline 23 KPDEP & -.537 & -.715 & -.472 & $-.737^{*}$ \\
\hline 24 RLTLTL & -.021 & $-.058^{* *}$ & $-.0025^{* *}$ & -.023 \\
\hline 25 ATAX & & .114 & $-.338^{*}$ & $-.325^{*}$ \\
\hline 26 FFMKT & -.097 & -1.164 & $-1.031^{* * *}$ & $-1.157^{*}$ \\
\hline 27 FLO1 & -.028 & -.030 & $-.027^{* *}$ & $-.024^{*}$ \\
\hline 28 FRGNO & & 2.831 & & -1.187 \\
\hline 29 PAY1 & $-.499^{*}$ & -.575 & $-.340^{*}$ & -.275 \\
\hline $30 \mathrm{PNCV}$ & & .183 & & $-.964^{* *}$ \\
\hline 31 SALTOR & $.807^{*}$ & $1.160^{* *}$ & & .346 \\
\hline 32 TRDVRA & & -.407 & & -.171 \\
\hline 33 VCAP & & .196 & $-.722 * *$ & $-.762^{* *}$ \\
\hline 34 VERN & & -.140 & $.383^{* * *}$ & $.497^{* * *}$ \\
\hline 35 VFLO & & .068 & & .132 \\
\hline 36 ABET & & .280 & $1.030^{* * *}$ & $1.173^{* * *}$ \\
\hline 37 cUTD & $1.592^{*}$ & $1.637^{*}$ & $1.426^{* * *}$ & $1.318^{* *}$ \\
\hline 38 DELE & & .170 & & .00038 \\
\hline 39 DMNE & & .097 & & -.239 \\
\hline 40 MRGIN & -.590 & -.780 & $-1.125^{* *}$ & -.858 \\
\hline 41 REVENA & $-9.233^{* * *}$ & $-11.011^{* * *}$ & & -.664 \\
\hline 42 ROEQ & $1.858^{*}$ & 1.968 & & .458 \\
\hline
\end{tabular}


Table 16.8 (continued)

\begin{tabular}{|c|c|c|c|c|}
\hline \multirow[b]{2}{*}{ Descriptor } & \multicolumn{2}{|c|}{ Regressions for Beta } & \multicolumn{2}{|c|}{ Regressions for Sigma } \\
\hline & Selected & All & Selected & All \\
\hline 43 AGRO & & -.241 & .367 & .090 \\
\hline 44 DMS5 & $.0075^{*}$ & $.088^{*}$ & & -.0070 \\
\hline 45 EGRO & & .230 & & .370 \\
\hline 46 OFFEX & & -.087 & & -.030 \\
\hline 47 RSKLGO & & .084 & & -.015 \\
\hline 48 ASSI & & -.146 & $-.177^{* * *}$ & $-.182^{* * *}$ \\
\hline 49 MKTS & & .000060 & -.000044 & -.000036 \\
\hline 59 ATOLM & & .0055 & & .0050 \\
\hline 60 ВВET & & -.468 & & .187 \\
\hline 61 вTOP & & .047 & & .073 \\
\hline 62 CAPT & $.208^{* * *}$ & $.352^{* * *}$ & $.138^{* * *}$ & $.188^{* * *}$ \\
\hline 63 DMYL & & .250 & $.554^{* * *}$ & $.589 * * *$ \\
\hline 64 ENTP & & .061 & & -.602 \\
\hline 65 ETOP & $1.464^{* *}$ & .673 & -.290 & -.846 \\
\hline 66 ETP5 & $-5.359^{* * *}$ & $-3.769^{*}$ & -1.056 & -1.259 \\
\hline 67 LIQU & & $-.026^{*}$ & -.012 & $-.034^{* * *}$ \\
\hline 68 MLEV & & -.115 & $.138^{*}$ & .112 \\
\hline 69 ECAP & $-.00040^{* * *}$ & $-.00048^{* * *}$ & & -.00011 \\
\hline 70 PTEQ & & .034 & & .071 \\
\hline 71 YILD & $3.120^{* *}$ & $5.432 * *$ & $3.089^{* * *}$ & $3.768^{* *}$ \\
\hline 72 YLD5 & -4.941 & $-6.286^{*}$ & -2.333 & -1.892 \\
\hline
\end{tabular}

Note: Significance levels, as derived from the appropriate $F$-statistic, are denoted as follows: ${ }^{*} 95$ percent; ${ }^{* *} 99$ percent; ${ }^{* *} 99.9$ percent.

Apparently this variable is interacting with other measures of leverage. Also, the degree of variability in capital structure (VCAP) was expected to be predictive of higher residual risk but, in fact, has a significant negative coefficient. Finally, one significant effect was not clearly predictable from our a priori expectations: the extent of federal funds market making activity (FFMKT) is found to be predictive of lower residual risk. This suggests that an active market-maker can better control its destiny. The reverse sign would have suggested that market-making leads to increased uncertainty, owing to speculative risk from unpredictable short-term movements in the federal funds market.

In prediction for beta, only one of these descriptors of operating characteristics achieves significance. Signs of the effects are typically the same, with the exception of PNCV and VCAP, where the expected positive signs occur, and VERN, where the expected positive sign is contradicted by a small negative coefficient.

Turning next to measures of earning success, the indicator for previous dividend cuts (CUTD) is a highly significant predictor of both higher 
systematic risk and higher residual risk. Operating margin (MRGIN) is predictive of lower systematic and residual risk. The ratio of operating revenue to total assets (REVENA) is likewise predictive of lower residual and systematic risk. Return on equity (ROEQ) is predictive of higher risk.

No measures of earnings growth are consistently important, though the indicator for an available earnings history is marginally predictive of higher systematic risk with a negligible effect on sigma. Of the two measures of size, only ASsI (asset size) achieves significance. The coefficients are somewhat greater in magnitude than they were in the previous regressions with asset/liability characteristics only, probably because of an interaction with the size of market capitalization descriptor (CAPT), to be discussed below. The coefficient for asset size (ASSI) in prediction of beta has changed sign and lost significance. Again, this is probably the result of interaction with the coefficient for market capitalization.

Finally, we come to measures of financial ratios and other characteristics that are dependent on the market valuation of common stock, taken in conjunction with income-statement and balance-sheet data. Here the nature of the effects must be interpreted with some care. First, the dummy variable for negligible yield (DMYL) is predictive of greater risk, as is to be expected. However, current yield is significantly predictive of higher risk. When this is contrasted with the negative coefficient for the five-year normal yield and for the payout ratio, it may be interpreted as a surrogate for a recent decline in the bank's circumstances. Current yield is defined as the ratio of the previous year's dividends to current price. This ratio is often high relative to the payout ratio, because of a recent pessimistic adjustment in the future prospects of the bank, which causes a reduction in the denominator (price) but is not yet reflected in the numerator (last year's dividends). Thus a high value of current yield, relative to past yield, often indicates that ihe circumstances of the bank have recently declined and is thus predictive of greater risk.

The same pattern of signs is seen in the earnings/price ratio. The normal earnings/price ratio (ETP5) is predictive of lower risk or, equivalently, a high price/earnings ratio is predictive of higher risk. This is consistent with a general property of growth-oriented firms, which is that the longer the apparent duration of the promised stream of future dividends, the greater is investment risk. The sign of the current earnings/ price ratio (ETOP) is also negative for sigma, but it is positive for beta. This last effect can possibly be understood again as indicating that the decline in the present price is reflective of a downward adjustment in future prospects, relative to recent earnings.

Greater liquidity (LIQU) is predictive of lower residual risk and has a smaller effect upon systematic risk. Finally, greater market capitalization (CAPT) is predictive of higher risk. It is important to note here that $(a)$ there is a substantial positive correlation (approximately . 72 in our sam- 
ple) between CAPT, the logarithm of market capitalization, and ASSI, the logarithm of total assets; and (b) their difference (ASSI - CAPT) is the logarithm of "the market valuation of each dollar of assets." This difference is thus a measure of the manner in which the bank is operated. Consequently, a positive coefficient for CAPT, in conjunction with a negative coefficient for ASSI, suggests that greater expected profitability with a given asset base results in higher risk.

Finally, table 16.9 reports the regression coefficients for the six dummy variables that bring in the regional characteristics of the banks. The regressions show that the typical New York money-center bank is much higher in systematic risk than the norm, but a little bit below normal in residual risk. West Coast banks are next highest in systematic risk and also a little above the norm in residual risk. The southeastern banks are significantly above normal in both the risk measures. All of the earlier regressions, reported in tables $16.6-9$, were also run in an alternative mode with regional dummy variables included. Happily, when the fundamental characteristics of banks are included, the regional dummies lose significance: the group as a whole generally lacked statistical significance (by the $F$-test), and when the regional variables were considered singly, only the dummy variable for the southeastern region was usually significant, with a small positive coefficient. Thus most of the regional differences in systematic and residual risk can be attributed to various fundamental characteristics of the banks.

Table 16.10 reports the overall adjusted $R^{2}$ statistics for the regressions in the earlier tables. In addition, adjusted $R^{2} \mathrm{~s}$ are reported for certain regressions of special interest which incorporate historical risk measures, as well as fundamental descriptors. The first row of the table relates to the assumption that all banks have identical risk levels in each period. $R^{2}$ in the predictive regression for beta is .2594 , indicating that this proportion of the variance of monthly bank common stock returns can be attributed to a common and identical dependence on the overall market return. $R^{2}$

Regressions with Only the Regional-Type Dummy Variabłes

\begin{tabular}{llll}
\hline & $\begin{array}{l}\text { Beta } \\
\text { Prediction } \\
\text { Rule }\end{array}$ & $\begin{array}{l}\text { Sigma } \\
\text { Prediction } \\
\text { Rule }\end{array}$ \\
\hline 73 DRMNY & $.239^{* * *}$ & -.035 \\
74 DRMON & .083 & .0048 \\
75 DRSE & $.135^{* * *}$ & $.116^{* * *}$ \\
76 DRMW & -.055 & $-.070^{* *}$ \\
77 DRSW & .031 & .041 \\
78 DRWC & $.217^{* * *}$ & $.095^{* *}$ \\
\hline
\end{tabular}

Note: Significance levels, as derived from the appropriate $F$-statistic, are denoted as follows: * 95 percent; ** 99 percent; ** 99.9 percent. 
Table 16.10

Summary of Adjusted $\boldsymbol{R}^{2}$ Statistics

\begin{tabular}{|c|c|c|}
\hline \multirow[b]{2}{*}{ Independent Variables } & \multicolumn{2}{|c|}{ Regression } \\
\hline & Beta & Sigma \\
\hline Constant & .2594 & .0887 \\
\hline Historical estimate & .2659 & .1052 \\
\hline $\begin{array}{l}\text { Historical estimate for beta and Bayesian } \\
\text { adjustment thereto }\end{array}$ & .2675 & - \\
\hline All market price variability descriptors & .2755 & .1096 \\
\hline Asset proportions and asset size & .2671 & .0929 \\
\hline Liability proportions and asset size & .2673 & .0933 \\
\hline $\begin{array}{l}\text { All asset/liability proportions and } \\
\text { asset size }\end{array}$ & .2690 & .0959 \\
\hline $\begin{array}{l}\text { Net asset/liability proportions and } \\
\text { asset size }\end{array}$ & .2685 & .0954 \\
\hline $\begin{array}{l}\text { Selected fundamentals (including market } \\
\text { valuation descriptors) }\end{array}$ & .2830 & .1222 \\
\hline $\begin{array}{l}\text { All fundamentals (including market } \\
\text { valuation descriptors) }\end{array}$ & .2829 & .1235 \\
\hline All descriptors & .2852 & .1321 \\
\hline
\end{tabular}

for the corresponding assumption for the prediction of sigma is .0887 , indicating that this proportion of the variance in the average absolute residuals in the pooled cross-section time series can be attributed to month-to-month differences in cross-sectional average residual variability.

The second row refers to the attained $R^{2}$ when the only descriptor is the historical estimate of the risk measure (beta and sigma, respectively). Next is the $R^{2}$ achieved in prediction of beta, where a Bayesian adjustment term for measurement error in historical beta is included along with the historical beta. The fourth row of the table gives results when all market-price-variability descriptors are incorporated.

The second section of the table gives $R^{2}$ for the various regressions including asset/liability descriptors and asset size. The third section reports the regressions including all fundamental variables. The final row reports the regressions including all descriptors.

It is encouraging that the regressions including all fundamentals but no others (i.e., market-price-variability descriptors are omitted) achieve nearly the same $R^{2}$ as the regressions that include the market-pricevariability descriptors as well. The increase in $R^{2}$ from use of all descriptors is $.0258(.2852-.2594)$ for beta, and .0434 (.1321 - .0887) for sigma. The prediction rule for beta based on all fundamentals attains 90 percent of this increase, while the prediction rule for sigma attains 80 percent. Thus the measures of the behavior of the stock price in the market add little to our ability to predict its subsequent variability in the 
market. Moreover, the fundamentals taken alone do substantially better than the market-price-variability descriptors taken alone. Since the market-price-variability descriptors include the natural Bayesian predictions from historical data, this result suggests that the explanatory power of the fundamental descriptors is fairly complete. Otherwise the historical descriptors would serve as surrogates for the omitted fundamental variables and would achieve substantial importance in the prediction of systematic and residual risk. Because of the small significance of the market-price variability descriptors, we chose to save space by omitting the tables referring to these regressions. It is sufficient to note that, in general, inclusion of the market-price-variability descriptors did not importantly affect the signs or significance of the fundamental variables.

The regressions reported thus far are related to the period from March 1969 through June 1977: thirty-three quarters and one partial quarter, or one hundred months. We also had available to us less complete data on a smaller sample of banks for a longer history (forty-five quarters). We divided this longer history into two intervals and fitted separate regressions to each interval to investigate the stability of the coefficients. Tests for significant changes in the structure of coefficients were either insignificant or barely exceeded the 99 percent critical level. This was encouraging in indicating that the structure of the risk relationships has not substantially changed in the recent past.

\subsection{Conclusions and Implications}

The central conclusion of the study is that systematic and residual risk in banks can be predicted from predetermined fundamental data. Prediction rules estimated in this way can serve a useful function in monitoring bank risk. The predictive significance of fundamental descriptors serves as a measure of the appropriateness of the descriptor as an indicator of risk, and hence as a target for regulation. For example, alternative formulas for capital adequacy can be validated and compared in terms of their predictive content.

The descriptors used in this study were restricted to the limited coverage of the COMPUSTAT data base and Keefe manual. It was not possible to test the various capital-adequacy formulas that are now used, since some data were missing. However, a number of natural descriptors of balance sheet, income statement, and operating variance could be computed. Some of these were found to be indicative of serious bank difficulties, in the sense that they produce substantial outliers when bank circumstances were aberrant. Perhaps more important, after the effect of the outliers was diminished by truncation of extreme values, the transformed descriptors were predictive of differences in risk across the full continuum of banks in the sample. 
The fundamental descriptors were rather successful in predicting differences in risk. A large number of descriptors were statistically significant. The historical measures of market-price variability added little to the explanatory power of the fundamentals. The fundamental information, taken as a group, explains more than the market-price-variability data.

Interestingly, the predictors of systematic and residual risk differ importantly. Only three of the ten best simple predictors of beta are also included among the ten best simple predictors of residual risk, and two of these are historical measures of market variability. Among the important simple fundamental predictors of beta are descriptors of size, dividend yield, equity capitalization, and the asset/long-term liability ratio. The most important simple predictors of residual risk are earnings variability, leverage in the capital structure (with common stock valued at book and market), and a measure of accounting beta. In the multiple-regression models, the signs of descriptors are generally the same for prediction of beta and residual risk, but the relative magnitudes are often significantly different.

Several aspects of the results are suggestive. For example, size (best measured by total assets or, alternatively, measured by market share or total value of common stock) is a good single predictor of beta: the larger the size of the bank, the higher the expected systematic risk. However, in the multiple regression models, size is only one among a number of important descriptors and loses its dominant role. Thus, the larger banks are clearly more exposed to systematic risk in the economy, but most causes for this exposure are captured by other descriptors in the model.

It is interesting that net federal funds borrowed (NFFBA) is a predictor of increased risk in regressions for both beta and sigma (statistically significant for beta), but that federal funds market-making activity (FEMKT) - defined as the volume of offsetting borrowing and lending-is predictive of lower risk (significant for sigma). This suggests that measures of risk based on the gross amount of federal funds borrowed are incorrect. Instead, net borrowing, being predictive of higher risk, should be used as an indication of increased leverage.

It is also interesting that the ratio of long-term debt to total assets is predictive of lower risk, confirming that long-term debt is a stabilizing influence that can be regarded as an element of capital. However, from the point of view of variability of the common stock price, senior liabilities constitute a leveraging device that increases investment risk, and it is not surprising that leverage due to senior long-term liabilities, whether measured in terms of the book value of capital (BLEV) or the market value of capital (MLEV), is a good simple predictor of increased risk. In the multiple regressions, BLEV is the more important descriptor. The two measures of leverage that are the best simple predictors of beta are the 
ratio of total assets to long-term liabilities (АTOLB) and the ratio of risk liabilities to long-term liabilities (RLTLTL). These are also effective simple predictors of residual risk. However, in the multiple regressions, with a number of other highly correlated leverage descriptors present, ATOLB is less significant, and the coefficient of RLTLTL changes sign.

No single descriptor in the model fully captures the profitability of the bank. One can think of profitability as the product of two ingredients: revenue per dollar of assets (REVENA) and operating profit per dollar of revenue (MRGIN). The former is a simple predictor of increased risk, but the sign changes in the multiple regressions for beta and sigma. Operating margin (MRGIN) is consistently a predictor of reduced risk, presumably because the bank's assets are being managed more effectively. The extent of prior dividend cuts (CUTD) is another strong and consistent predictor of increased risk, which amplifies the effect of operating margin.

It is natural, from the point of view of capital asset theory, to assign capital costs for assets and liabilities in relation to the contribution of the item to systematic risk. For this purpose, the adjustments for systematic risk obtained from table 16.6 are the appropriate estimates. For example, the beta coefficients for municipal bonds and for real estate loans differ by $(1.724-(-.737))=2.461$. In a typical bank, after correction for the leverage in the capital structure, the beta of municipal bonds is estimated to be 2.461 greater than for real estate loans. Since the contribution to beta per dollar of assets in municipals significantly exceeds the contribution to beta from real estate loans, the capital cost assessed per dollar of municipal investment should be correspondingly greater. Investment securities other than municipals and trading account securities show up as other low-beta assets. On the liability side, capital accounts, demand deposits, and foreign deposits show as low-beta liabilities, and consumer time deposits and net federal funds borrowed show as high-beta liabilities.

A number of measures of aggressiveness in the bank's growth policy show up as predictive of higher risk, particularly in regard to residual risk. These include the normal payout ratio and normal yield (both indicators of lower retention rates and hence of lower growth), which are predictive of lower risk, and the growth rate of total assets, predictive of higher residual risk.

Having discussed the prediction of differences in risk, we should mention the absolute risk levels in our sample of banks. Natural measures of risk are averages of beta, computed relative to the CRSP RETV index over a sixty-month history, and the average residual standard deviation (sigma) in these regressions. The sample average beta, with each bank weighted by the market value of outstanding common stock (market capitalization), was . 71 for the sixty-month period ending in January 1969, and was 1.10 for the sixty-month period ending in January 1977. The equal- 
weighted average increased similarly, from .63 to .96 . For residual risk, defined as the standard deviation of monthly residual returns, the capitalization-weighted average increased from .051 in the early period to .072 in the latter, while the equal-weighted average increased from .054 to .068 . These increases signal increased difficulty in bank regulation. Increased systematic risk in the banking system raises the probability of widespread disaster, however small the probability may be, since the aggregate net worth of all banks is more unstable. Increased residual risk is associated with more frequent difficulties for individual banks, independent of the economy as a whole. The prevention of failure has become more difficult, and the insurance liability has grown because of the higher probability that extreme returns will occur as a result of the intrinsic uncertainty in the bank's operations.

\section{Appendix: The Model Used}

The Model and Definitions

The following definitions will be used:

$$
\begin{aligned}
& t=1,,, T \text { the month, varying from } 1 \text { to } T \\
& n=1,,, N \text { the index of the individual bank, varying } \\
& \text { from } 1 \text { to } N \\
& j=1,,, J \text { the index of an individual descriptor, with } \\
& J \text { descriptors } \\
& \left(1+i_{F t}\right) \text { the riskless return in month } t \text {, defined as } \\
& \text { the four- to six-month prime commercial paper } \\
& \text { rate at the start of that month } \\
& \left(1+i_{M t}\right) \text { the market return in month } t \text {. We use the } \\
& \text { CRSP RETV (value-weighted returns, } \\
& \text { including dividends) } \\
& \left(1+i_{n t}\right) \text { the return on security } n \text { in that month } \\
& r_{M t}=\ln \left(1+i_{M t}\right)-\ln \left(1+i_{F t}\right) \text { the logarithmic } \\
& \text { excess return for the market index, } \\
& \text { closely similar to the arithmetic excess } \\
& \text { return } i_{M t}-i_{F t} \text {. } \\
& r_{n t}=\ln \left(1+i_{n t}\right)-\ln \left(1+i_{F t}\right) \text { the logarithmic excess } \\
& \text { return relative on security } n \\
& x_{j n t} \text { the value of the } j \text { th descriptor for bank } n \\
& \text { in month } t \text {. }
\end{aligned}
$$

In each month $t$, let the probability distribution of logarithmic return relatives be determined by the model:

$$
r_{n t}=\alpha+\beta_{n t} r_{M t}+e_{n t}, \quad n=1, \ldots, N_{t}
$$


with

$\alpha=$ overall average excess return, approximately zero

$\beta_{n t}=$ systematic risk coefficient of bank $n$ in month $t$

$e_{n t}=$ residual return of bank $n$ in month $t$

$N_{t}=$ number of banks in month $t$.

Let the model for $\beta_{n t}$ be:

$$
\beta_{n t}=b_{0}+b_{1} x_{1 n t}+\ldots+b_{J} x_{J n t},
$$

for all time periods $t$ and banks $n$, where $b_{0}, \ldots, b_{J}$ are the coefficients of the prediction rule for systematic risk. Let

$$
E\left(e_{n t}\right)=0, \operatorname{COV}\left(e_{n t}, r_{M t}\right)=0 \text { for all } t,
$$

and let $\sigma_{n t}^{2}$ be the residual variance of $e_{n t}$. The model for the standard deviation is:

$$
\sigma_{n t}=\bar{s}_{t}\left(s_{0}+s_{1} x_{1 n t}+\ldots+s_{J} x_{J n t}\right),
$$

where $\tilde{s}_{t}$ is the typical cross-sectional standard deviation in month $t$ and $s_{0}$, $\ldots, s_{J}$ are the coefficients of the prediction rule for residual risk.

Define:

$$
\begin{aligned}
\delta_{n t}= & E\left(\left|e_{n t}\right|\right), \text { the mean absolute residual } \\
& \text { return for security } n \text { in month } t \\
\gamma= & \sigma_{n t} / \delta_{n t} \text {. It may be shown that } \\
& \gamma=\sqrt{1+c^{2}(|x|) \text { when } E(x)=0, \text { where }} \\
& c(|x|) \text { is the coefficient of variation of }|x| .
\end{aligned}
$$

Then the model for residual risk can be rewritten as:

$$
\delta_{n t}=\bar{\delta}_{t}\left(s_{0}+s_{1} x_{1 n t}+\ldots+s_{J} x_{J n t}\right),
$$

where $\bar{\delta}_{t}=\frac{1}{\gamma}\left(s_{t}\right)$ is the typical mean absolute residual in month $t$.

The Estimation Approach

Each regression is run over the pooled sample of all data points $n$ in all months $t$. The estimation proceeds in two passes: Each pass consists of two forms of regression. The first is a "market-conditional" regression for beta. In pass 1 , it takes the form:

$$
\begin{aligned}
r_{n t}=\alpha+b_{0}\left(r_{M t}\right)+b_{1}\left(x_{1 n t} r_{M t}\right)+b_{2}\left(x_{2 n t} r_{M t}\right) & \\
+\ldots+b_{J}\left(x_{J n t} r_{M t}\right)+e_{n t} . & n=1, \ldots, N_{t} \\
& t=1, \ldots, T
\end{aligned}
$$

This regression provides preliminary estimates of the prediction rule for 
beta, with coefficients $\hat{b}_{0}, \hat{b}_{1}, \ldots, \hat{b}_{J}$. Then, for each bank in each month, a preliminary prediction of beta is computed as:

$$
\hat{\beta}_{n t}=\hat{b}_{0}+\hat{b}_{1} x_{1 n t}+\ldots+\hat{b}_{J} x_{J n t} .
$$

These preliminary predictions for beta are substituted to obtain predictions of residual returns defined as:

$$
\hat{e}_{n t}=r_{n t}-\hat{\beta}_{n t} r_{M t} \text {. }
$$

The next regression is fitted to estimate residual risk. It takes the form:

$$
\frac{\left|\hat{e}_{n t}\right|}{\delta_{t}}=s_{0}+s_{1}\left(x_{1 n t}\right)+s_{2}\left(x_{2 n t}\right)+\ldots+s_{J}\left(x_{J_{n t}}\right)+\varepsilon_{n t} \text {, }
$$

(5) where:

$$
\delta_{t}=\frac{\sum_{n=1}^{N_{t}} w_{M n t}\left|\hat{e}_{n t}\right|}{\sum_{n=1}^{N_{t}} w_{M n t}},
$$

where $\boldsymbol{w}_{M n t}$ is the capitalization weight for bank $n$ at time $t$, equal to the proportion of the market value of all equity in that bank. Thus, $\bar{\delta}_{t}$ is the capitalization-weighted, cross-sectional average of absolute residual returns. This regression obtains the preliminary prediction rule for relative specific risk, with estimated coefficients $\hat{s}_{0}, \ldots, \hat{s}_{J}$.

Pass 2 involves repetition of each of these equations using generalized least squares. To accomplish generalized least squares, each observation is weighted inversely to its disturbance variance. In this model, the disturbance variance is proportional to the variance of the bank's residual return in both regressions! Therefore we compute for each bank $n$ in each month $t$ a prediction of residual risk provided by:

$$
\hat{\sigma}_{n t}=\gamma \bar{\delta}_{t}\left(\hat{s}_{0}+\hat{s}_{1} x_{1 n t}+\ldots+\hat{s}_{J} x_{J n t}\right) .
$$

To avoid extremely small predicted variances, $\hat{\sigma}_{n t}$ is set equal to $(1 / 3) \gamma \bar{\delta}_{t}$ if the prediction for relative standard deviation is less than $(1 / 3)$; hence the kink in figure 16.2. Then the market-conditional regression for beta is repeated, with observations divided by their predicted residual risk.

Type B Regression

$$
\frac{r_{n t}}{\hat{\sigma}_{n t}}=\alpha\left(\frac{1}{\hat{\sigma}_{n t}}\right)+b_{0}\left(\frac{r_{M t}}{\hat{\sigma}_{n t}}\right)+\ldots+b_{J}\left(\frac{x_{I n t} r_{M t}}{\hat{\sigma}_{n t}}\right)+e_{n t}^{\prime} .
$$

These weights obtain estimates that are efficient in the statistical sense of maximal accuracy. The intuitive meaning of the weights is best understood by noting that banks with low residual risk are given greater weights than banks with high residual risk, with the weights in proportion to $1 / \hat{\sigma}_{n t}^{2}$. Also, the weights vary over time periods owing to fluctuations in $\delta_{t}: A$ 
cross section with the highest level of residual variance is given about one-sixth the weight of a cross section with a very low level of residual variance. Predictions for systematic risk in tables 16.5, 16.6, 16.8 and 16.9 were obtained from type $B$ regressions.

The fitted betas from the type $\mathrm{B}$ regression are used to recompute the estimates of residual returns $e_{n t}$. With these modified residual returns, the next step is to carry out the second-pass regression for residual risk.

Type R Regression

$$
\frac{\left|\hat{e}_{n t}\right|}{\hat{\sigma}_{n t} \bar{\delta}_{t}}=s_{0}\left(\frac{1}{\hat{\sigma}_{n t}}\right)+s_{1}\left(\frac{x_{1 n t}}{\hat{\sigma}_{n t}}\right)+\ldots+s_{J}\left(\frac{x_{J n t}}{\hat{\sigma}_{n t}}\right)+\varepsilon_{n t}^{\prime} .
$$

Notice that the same weights are used here as in the prediction rule for beta. Predictions for residual risk in tables $16.5,16.7,16.8$, and 16.9 were obtained from type $\mathrm{R}$ regressions.

The rationale behind this estimation approach is derived in detail in Rosenberg and Marathe (1979). The only changes in the present approach, relative to the approach set forth in that paper, are $(a)$ the ignoring of extramarket covariance in the second-pass generalized leastsquares regression for beta, and $(b)$ the use of a regressior. for absolute residual returns rather than for squared residual returns in the type $\mathrm{R}$ regressions for residual risk. The first change simplified the computational procedure and will be reconsidered if time permits. The second change was taken in part because, in the presence of the slightly longtailed distributions of security returns that we find, the use of absolute residual returns should slightly improve statistical efficiency. 

